\title{
A Method to Correct Eddy Covariance Flux Underestimates under an Advective Environment for Arid or Semi-arid Regions
}

Hongbo Su ${ }^{1}$, Yongmin Yang ${ }^{2,3,4}$, Lina Xu ${ }^{5,1}$, José L. Chávez ${ }^{6}$, Steven R. Evett ${ }^{7}$, Terry A. Howell ${ }^{7}$, Jing $\operatorname{Tian}^{2}$, Shaohui Chen ${ }^{2}$, Jinyan Zhan ${ }^{8}$ 


\begin{abstract}
Water scarcity is one of the main factors limiting agricultural development in arid or semi-arid areas. Accurate Evapotranspiration (ET) observations and estimations are crucial in water cycle studies to estimate water losses from the terrestrial surfaces to the atmosphere to close the regional water budget. The eddy covariance (EC) method is an important technique measure ET and other land surface energy fluxes. However, the underestimation of energy fluxes and the problem of EC energy balance non-closure are far from solved. In this study, a new method is proposed to account for advection in order to correct EC data under advective environments. This advection based method was applied to data from Bushland, TX, which is subject to dry air and strong winds. Observations from two identical EC systems as well as two precision monolithic weighing lysimeters were used in this analysis. Both EC sites showed significant underestimates of evapotranspiration (ET) compared with lysimeter measurements. The daily energy balance closure for NE01 and SE02 sites were 0.78 and 0.74 respectively. The advection correction method provided improved performance in daytime, and it is more suitable for ET estimate than forcing closure under the advective environment. For nighttime, two methods (NCM1 and NCM2) were proposed to correct EC underestimates. Finally, all the corrected ET values were compared with the lysimeter measurements. For NE01 site, the MAD (mean absolute deviation) and the RMSD (root mean square deviation) were $47.72 \mathrm{~W} / \mathrm{m}^{2}$ and $67.66 \mathrm{~W} / \mathrm{m}^{2}$, respectively; and the $\mathrm{r}^{2}$ (coefficient of determination) was 0.85 . For SE02 site, the MAD and RMSD were $30.59 \mathrm{~W} / \mathrm{m}^{2}$ and $44.43 \mathrm{~W} / \mathrm{m}^{2}$; and the $\mathrm{r}^{2}$ was 0.93 . The statistical measures illustrated that the proposed methods are functional and appropriate under an advective environment. The accurate estimate of actual evapotranspiration will benefit both the strategic planning of optimal water uses and the improved understanding the environmental and hydrological processes.
\end{abstract}

Keywords: water management, energy balance closure; eddy covariance; advection

\title{
1. 1. Introduction
}

With a rapid growth of population, agriculture, and industry, the demand for water has increased gradually across the world (Shi et al., 2015). As a result, agricultural crops have been damaged by drought severity due to climate changes that in turn contribute to water scarcity (Shin and Jung, 2014; Deng and Zhao 2015). The sustainable management of water resources to address the water scarcity issue requires an accurate estimation of water losses from the terrestrial surfaces to the atmosphere in the arid or semi-arid ecosystems (Vanino et al., 2015; Li et al., 2015). Evapotranspiration (ET) is an very important process that relates to energy and water exchange between hydrosphere, atmosphere and biosphere (Brutsaert, 2005; Priestley and Taylor, 1972). The accurate observation and estimation of ET is extremely important to further our understanding of global climate change, land-atmosphere interaction, water cycles and ecological studies (Betts et al., 2004; Goutorbe et al., 1993; Kustas et al., 
2002; Lawrence et al., 2009; Shuttleworth, 2007). The ET from the land surface is approximately 60$65 \%$ of global precipitation; and can be as large as $80 \%$ in arid and semiarid regions of the world (Brutsaert, 1982; Rosenberg et al., 1983). Crop evapotranspiration response to different planting scenarios and meteorological conditions plays a significant role in optimizing crop planting patterns, resolving agricultural water scarcity and facilitating the sustainable use of water resources (Liu et al., 2015). There is still a big knowledge gap on how evapotranspiration varies in responding to changing temperature and precipitation over different zones in terms of supply and demand regime for ET (Liu, et al., 2013; Deng et al., 2015). Accurate ET observations and estimations are crucial in water cycle studies and will benefit water management in arid and semiarid areas of the world (Wang et al., 2015).

Many methods have been proposed for measuring ET or its components evaporation $(E)$ and transpiration $(T)$ at various scales (Su et al., 2005, 2007; Tian et al., 2013). Sap-flow and porometer are often used to measure transpiration from individual plants or leaves. Weighing lysimeters and other mass balance methods are used to measure ET at local scales. Many methods have been used for quantifying energy and water balance components and ET at various scales, including Bowen ratio systems, Eddy covariance (EC) and scintillometers (Evett, et al., 2012). Remote sensing based ET models can be suitable for estimating ET at regional scale. Among these observation techniques, EC observations are often used to test the remote sensing based ET models (Cleugh et al., 2007; Kustas et al., 2006; McCabe and Wood, 2006; Wang et al., 2006; Chávez et al., 2005; Yang et al., 2012, 2013, 2015). However, many problems related to EC have not been fully solved. Firstly, field observations of surface heat and water vapor fluxes often fail to reach closure of the surface energy budget (Chávez et al., 2009; De Bruin et al., 2005; Foken, 2008; Foken et al., 2006). Tanaka et al. (2001) found the surface energy balance was not closed in the GAME/Tibet experiment; the closure ratio in a typical clear day was as small as 0.67 or $67 \%$. Li et al. (2005) evaluated the observations from ChinaFlux and found imbalance was prevalent for all observation sites. Several reasons related to the lack of closure of the surface energy budget have been discussed by Mahrt (1998). The soil heat flux is an important term in the energy balance term; the uncertainties related to the measurements of the soil heat flux may be one of the reasons for the energy balance non-closure, but soil heat flux is a minor component of the energy balance when vegetated surfaces are considered, which is often the case. Heusinkveld et al. (2004) tested a new approach utilizing a high temporal resolution of soil heat flux measurements at the surface, and they found that the energy balance closure can be improved greatly. However, this research was limited for a sandy desert and a range of other land surface types need yet to be examined. Foken et al. (2006) discussed several reasons for the energy balance closure problem in the surface layer and pointed out the EC method underestimates turbulent fluxes in the case of ogives converging when measuring lasts longer than the typical averaging interval of $30 \mathrm{~min}$. Additionally, they pointed out that advection and non-steady state conditions may be the main reasons for the energy balance closure problem. The Energy Balance Experiment (EBEX-2000) (Oncley et al., 2007) studied the ability of state-of-the-art measurements to close the surface energy balance. All major terms of surface energy balance were measured at nine sites; also an estimate of heat storage in the plant canopy was conducted. The resultant imbalance was $10 \%$ and still exceeded the estimated measurement error. They speculated the horizontal advection in the layer between the canopy top and the height of flux measurement may have led to this imbalance. Foken (2008) reviewed 20 years of research on the energy balance closure problem. He pointed out that the assumptions that measurement errors, or 
storage terms, are the major reasons for the energy balance problem do not hold. Instead, he indicated that the exchange processes at larger scales of the heterogeneous landscape have a significant influence. Recently, Leuning et al. (2012) attributed the energy balance problem to eight reasons. They concluded that the imbalance of energy balance closure for daily averages is explicable by horizontal and vertical advective flux divergences. For the half-hour time scale, the energy balance closure problem may result from all sources of measurement and data processing. Secondly, the correction methods proposed by Twine et al. (2000) have often been used. However, there is not much knowledge about the accuracy of these correction methods. In their study, the results from the method that forces closure were tested using observations from another EC system. This validation is not sufficient, because both observations were from EC systems. The limitations of the EC measurements may exist in both EC systems. Therefore, testing using an alternative means of observation may provide more insight. Allen et al. (2011a) reviewed the basic principles of ET measuring systems and discussed the causes of error and biases to each systems, they further pointed out appropriate corrections are necessary to EC measurements.

Advection having great impact on ET has been reported for many field measurements. Commonly in semi-arid and arid irrigated environments, ET can exceed the net incoming radiation due to the advection from the surrounding landscape. Oke (1979) found daily ET from a mini-lysimeter exceeded the net radiation. Rijks (1971) found evaporation rate was 1.8 times greater than the supply of net radiation. Wang et al.(1993) found significant "desert-oasis effect" in the Heihe River Basin Field Experiment (HEIFE). Tolk et al. (2006a) found ET was greatly enhanced by advection in the semiarid regions of the southern High Plains. Allen et al. (2011b) also found that the 24-h ET from alfalfa measured by lysimeters was larger than the net radiation (Fig.1 in that paper). To date, there is still insufficient study to quantify advection effects in the field. Liston (1995) applied a numerical atmospheric boundary layer model to simulate local advection on snow cover. However, this method required detailed spatial knowledge of the patch size, wind direction and fetch distances and was computationally intensive. Lee et al. (2004) discussed various advection scenarios using a formula that related the ratio of eddy diffusivities for sensible to water vapor and the Bowen ratio. Prueger et al. (1996) and Granger et al. (2002) quantified local advection using the change of horizontal transport of energy content in the air layer below the boundary layer height. Accurate temperature and wind profiles are needed in these types of studies. Furthermore, advection has great impact on ET as well as on other surface energy balance components. Improving the study of advection becomes necessary to solve the energy balance closure problem when using an eddy covariance system.

To clearly address the advection problem, short period (minutes to hours) ET observations with high accuracy are necessary. Lysimeters are very important devices for measuring water use by vegetation and percolation of water through soils, partially because they do a direct measurement of the mass of water lost to ET. A weighing lysimeter involves weighing a container of soil that is planted with the same vegetation as its surroundings. The measurement accuracy of ET by lysimeters can be affected by many additional factors, such as non-uniform vegetation and soil conditions in the surrounding field, personnel traffic, and cultivation operations. More details of the lysimeter history can be found in Howell et al. (1991).When properly installed and managed, a weighing lysimeter can yield the most accurate ET data. Chávez et al. (2009) indicated that the lysimeter accuracy was sufficient to determine ET rates as small as 0.05 to $0.1 \mathrm{~mm}$ over time periods of $30 \mathrm{~min}$ or longer. 
Therefore, observations from large precision monolithic weighing lysimeters can be used to assess the accuracy and limitations of EC systems. In this paper, a new approach was applied to characterize the advection effects, and a new model was proposed to correct the EC underestimates in an advective environment. Section two presents a brief description of the theory and methodology, and section three introduces the study area and observations used in this study. Section four firstly assesses the accuracy of EC, and then presents the diurnal advection in the advective environment. In the remainder of section four, the EC observations are corrected with the newly developed model and the measurements from precision lysimeters are used to test the results. Section five discusses the limitations of the work and the final section provides a conclusion.

\section{Methodology}

\subsection{The surface energy balance}

Monteith (1965) made a good analogy of evaporation as a commercial transaction: "wet surface sells water vapour to its environment in exchange for heat. The heat can be supplied by solar radiation, turbulent transfer from atmosphere, and conduction from the soil." Figure 1 defines the control volume for the thermal energy balance. When advection is negligible, the energy balance equation can be expressed with Figure 1 (A). For a simple lumped system, when effects of unsteadiness, ice melt, photosynthesis, within canopy heat storage and lateral advection can be neglected, the land surface energy balance is written as (Brutsaert, 1982):

$$
\left(R_{n}-G\right)=H+L E
$$

where $R_{n}$ is the net radiation, $G$ is the soil heat flux, $H$ is the sensible heat flux and LE is the latent heat flux. This equation is often applied to evaluate the surface energy balance of EC measurements. In the above equation, advection is generally omitted in the surface energy balance equation, which may be applicable to non-advective and homogeneous surfaces. Guo and Schuepp (1994) pointed out the surface energy balance is limited by the assumption that the surface heterogeneity only affects the partition of the net available energy between sensible and latent heat flux. They state this assumption essentially excludes the presence of the horizontal heat flux over the surface that is responsible for transporting a portion of heat between patches. Evaporative demand is high in arid and semi-arid areas due to regional or local advection, often resulting in ET significantly exceeding the local available energy (net radiation minus soil heat flux) (De Bruin, 2005; Evett, 2012a). Monteith (1965) showed a diagram to illustrate the advection and change in evaporation rate when air blows from dry surface to wet surface (Figure 11 in his paper). He further pointed out the vertical flux of water vapour at the observation height will not be equal to the flux at the surface under such a circumstance. 

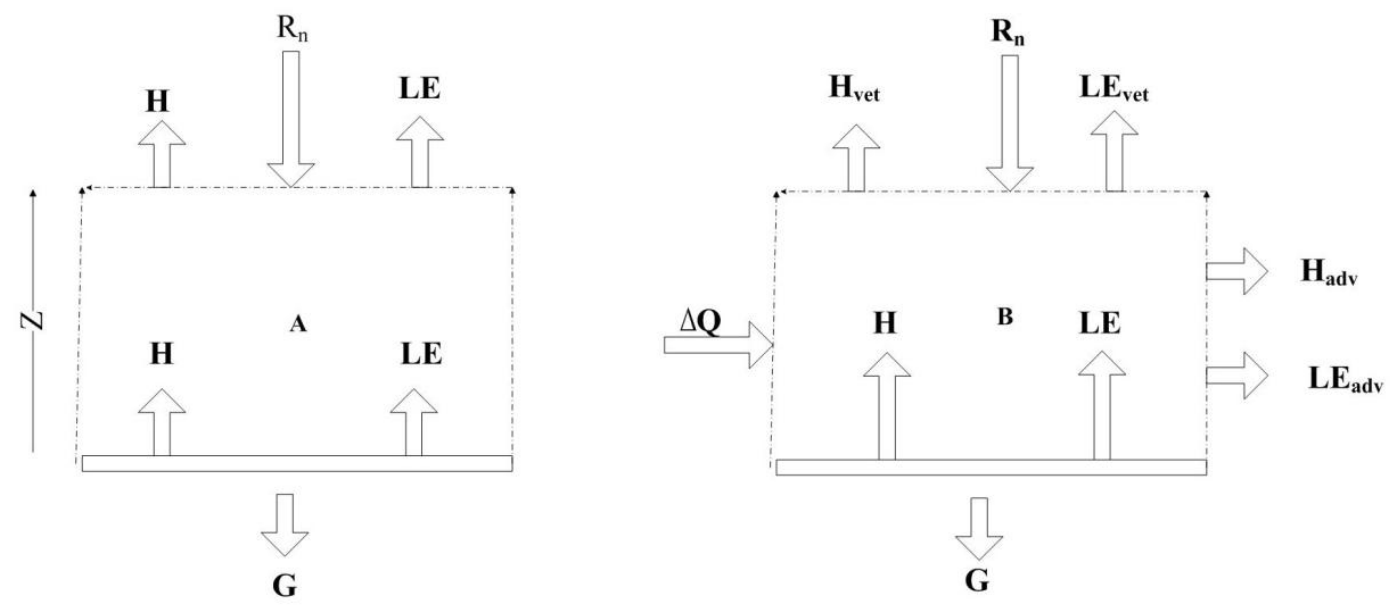

Figure 1. Control volume for thermal energy balance.

Accounting for energy from surrounding areas due to regional or local advection, the energy balance equation can be written as (Figure $1 \mathrm{~B})$ :

$$
\left(\mathrm{R}_{\mathrm{n}}-\mathrm{G}\right)+\Delta \mathrm{Q}=\mathrm{H}+\mathrm{LE}=\mathrm{H}_{\mathrm{vet}}+\mathrm{LE}_{\mathrm{vet}}+\mathrm{H}_{\mathrm{adv}}+\mathrm{LE}_{\mathrm{adv}}
$$

where $\Delta \mathrm{Q}$ is the energy transported from surrounding areas due to advection. $\mathrm{H}_{\mathrm{vet}}$ is the sensible heat flux in the vertical direction, $\mathrm{LE}_{\mathrm{vet}}$ is the latent heat flux in the vertical direction, $\mathrm{H}_{\mathrm{adv}}$ and $\mathrm{LE}_{\mathrm{adv}}$ are sensible and latent heat flux derived (or provided) from heat advection in the horizontal direction. A lysimeter can provide a direct measurement of LE under an advective environment, but $\Delta \mathrm{Q}$ and $\mathrm{H}_{\mathrm{adv}}$ are difficult to measure directly. Monteith (1975) pointed out that advection is often neglected in energy balance studies, more because it is notoriously difficult to estimate rather than because it is actually too small (mainly in humid climates) to be important. Many experiments indicated advection would directly alter the boundary conditions, such as air temperature, humidity and wind speed (De Bruin, 2005; Tolk et al., 2006a,b; Liu et al., 2009 Liu et al. 2011). To promote generalization, it is assumed that regional and local advection is embodied by prescribed meteorological conditions.

\subsection{The penman equation and the energy balance}

The Penman equation for estimating evaporation from water surfaces was essentially derived from the energy balance that considers both net radiation input (including solar and long-wave radiation) and convective heat exchange between the water and the atmosphere (Penman, 1948). The Penman equation is as follows:

$$
\mathrm{E}_{\mathrm{p}}=\frac{\Delta}{\Delta+\gamma}\left(\mathrm{R}_{\mathrm{n}}-\mathrm{G}\right)+\frac{\gamma}{\Delta+\gamma} \mathrm{E}_{\mathrm{a}}
$$

where $\Delta$ is the slope of the saturation vapor pressure vs. air temperature curve, $\gamma$ is the psychrometric constant, $\mathrm{E}_{\mathrm{a}}$ is the air drying power and the other terms were previously defined. The first term is often called the radiation forcing part and represents the rate at which water evaporates into saturated air. The second part is often called air drying power and represents the rate of latent heat flux due to difference in air temperature and vapor pressure between the surface and the atmosphere at a screen 
height. Monteith (1965) and Eagleson (2002) used the psychrometric chart to illustrate the Penman evaporation formula. More details of the equation can be found in their papers.

For the $E_{a}\left(\mathrm{~W} / \mathrm{m}^{2}\right)$ term in the above equations, Brutsaert (1982) proposed an equation to include the effect of stability in the wind function. The formula can be written as:

$$
\mathrm{E}_{\mathrm{a}}=\frac{\rho_{\mathrm{a}} \mathrm{C}_{\mathrm{p}}\left(\mathrm{e}_{\mathrm{a}}^{\mathrm{s}}-\mathrm{e}_{\mathrm{a}}\right)}{\gamma \mathrm{r}_{\mathrm{a}}}=\frac{\mathrm{k}^{2} \mathrm{u}_{*} \rho_{\mathrm{a}} \mathrm{C}_{\mathrm{p}}\left(\mathrm{e}_{\mathrm{a}}^{\mathrm{s}}-\mathrm{e}_{\mathrm{a}}\right) \gamma^{-1}}{\left(\ln \left[\frac{\mathrm{z}-\mathrm{d}_{0}}{\mathrm{Z}_{\mathrm{om}}}\right]-\psi_{\mathrm{m}}\left[\frac{\mathrm{z}-\mathrm{d}_{0}}{\mathrm{~L}}\right]\right)\left(\ln \left[\frac{\mathrm{z}-\mathrm{d}_{0}}{\mathrm{Z}_{\mathrm{oh}}}\right]-\psi_{\mathrm{h}}\left[\frac{\mathrm{z}-\mathrm{d}_{0}}{\mathrm{~L}}\right]\right)}
$$

where $\rho_{\mathrm{a}}\left(\mathrm{kg} / \mathrm{m}^{3}\right)$ is the air density, $\mathrm{k}=0.4$ is von Karman's constant, $\mathrm{u}_{*}(\mathrm{~m} / \mathrm{s})$ is the friction velocity, $\mathrm{C}_{\mathrm{p}}\left(1,013 \mathrm{Jkg}^{-10} \mathrm{C}^{-1}\right)$ is the specific heat of air at a constant pressure. $r_{\mathrm{a}}$ is the aerodynamic resistance $(\mathrm{s} / \mathrm{m}) . \mathrm{e}_{\mathrm{a}}^{\mathrm{s}}$ is the saturation vapor pressure of the air $(\mathrm{kPa}), \mathrm{e}_{\mathrm{a}}$ is the actual vapor pressure of the air $(\mathrm{kPa})$. The quantity $\left(\mathrm{e}_{\mathrm{a}}^{\mathrm{s}}-\mathrm{e}_{\mathrm{a}}\right.$ ) is often termed the water vapor pressure deficit (VPD, $\left.\mathrm{kPa}\right)$; $\mathrm{L}(\mathrm{m})$ is the Monin-Obukhov atmospheric stability length; $\mathrm{Z}(\mathrm{m})$ is the wind speed measurement height above the surface; $Z_{o m}(m)$ is the roughness length for momentum transfer; $Z_{o h}(m)$ is the roughness length for heat and vapor transfer; $\mathrm{d}_{0}(\mathrm{~m})$ is the zero-plane displacement height; and $\psi_{\mathrm{m}}$ and $\psi_{\mathrm{h}}$ are the atmospheric stability correction functions. More details of this model can be found in the paper by Katul and Parlange (1992).

Potential ET is defined as the amount of evaporation that would occur if sufficient water supply were available. In other words, potential ET is referred to as the available energy that could be used for ET (no positive sensible heat flux). The two-term structure in the Penman equation provides an interpretation of local or regional advection (Brutsaert, 1982). The first term of the Penman equation is considered as a lower limit for evaporation from moist surfaces and often referred as the equilibrium evaporation, while the second term is interpreted as a departure from the equilibrium state. That is, the equilibrium evaporation occurs when the air, in contact with a wet surface over a large enough fetch, tends to become vapor saturated and the air drying power, in the Penman equation, tends to zero. Brutsaert (2005) further pointed out that true equilibrium conditions are rare even over the ocean, since the atmospheric boundary layer is continually responding to unsteady large-scale weather patterns such that it tends to maintain a humidity deficit even over the ocean. The simple review above indicates advection may be common over the earth surface. Meteorological variables, such as air temperature, humidity and wind speed can directly drive the advective effects.

Advection can be characterized with potential evaporation and available energy. If advection can be neglected (Figure $1(A)$ ), available energy $\left(R_{n}-G\right)$ is the only source of energy that can be partitioned to the latent and sensible heat flux. Therefore, the potential ET or the evaporation rate for the wet limit is equal to available energy under such circumstances.

$$
\operatorname{Ep}=\left(R_{\mathrm{n}}-\mathrm{G}\right)
$$

Under such condition, $\mathrm{H}$ will equal zero and the control volume will reach to isothermal condition. This condition may be rare even over the ocean. However, in most conditions advection may not be neglected easily under heterogeneous surfaces or irrigated areas in arid and semi-arid areas (Figure 1 (B)). Under such conditions, the energy and water vapor transported by strong wind from the surrounding area carrying different air temperature or humidity can greatly influence the evaporation rate. Potential ET or the evaporation rate for the wet limit will differ from the local vertical available energy. 


$$
E_{p} \neq\left(R_{n}-G\right)
$$

Advection is accounted for in the $\mathrm{E}_{\mathrm{p}}$ formulation, since observed air temperature, wind speed and VPD is directly used. Compare the potential ET or the evaporation rate for the wet limit for two cases (Figure 1 (A) and (B)), advection is responsible for the difference. Therefore, advection can be characterized with the difference between potential ET and available energy.

$$
\Delta \mathrm{Q}=\mathrm{Ep}-\left(\mathrm{R}_{\mathrm{n}}-\mathrm{G}\right)=\frac{\gamma}{\Delta+\gamma}\left(\mathrm{E}_{\mathrm{a}}-\left(\mathrm{R}_{\mathrm{n}}-\mathrm{G}\right)\right)
$$

A similar concept was by Katul and Parlange (1992). Monteith (1965) provided a general explanation related to the latent heat and available energy (Eq. 22 in his paper). It is convenient to rewrite the expression for the potential evaporation (surface resistance equal zero) and available energy as follows:

$$
\frac{E_{p}}{R_{n}-G}=\frac{\Delta / \gamma+r_{i} / r_{a}}{\Delta / \gamma+1}
$$

where

$$
r_{i}=\rho_{a} C_{p} \frac{e_{a}^{s}-e_{a}}{\gamma\left(R_{n}-G\right)}
$$

Monteith (1965) termed $r_{i}$ as 'climatological resistance'. Several useful deductions can be made based on the above equations.

(i) If $r_{i}$ equals $r_{a}, E_{a}$ will equal $\left(R_{n}-G\right)$ and $\Delta Q$ will equal zero. Under such conditions, advection can be omitted in the energy balance equation.

(ii) If $r_{i}$ is very large in comparison with $r_{a}$, which might occur when winds are strong and the air flow is rather dry, then $E_{a}$ will be larger than $\left(R_{n}-G\right)$ and advection will enhance the ET rate.

(iii) If $r_{i}$ is small in comparison with $r_{a}$, which might occur when winds are weak and the air flow is humid, then $E_{a}$ will become smaller than $\left(R_{n}-G\right)$ and advection will result in depression of $E T$ rate.

To facilitate the understanding of advection, a theoretical VPD (VPD theory) for energy balance condition can be derived. If advection is neglected (Figure 1(A)), $E_{P}$ is equal to available energy. Combining equation (3), (4) and (5) the following equation is derived:

$$
\operatorname{VPD}_{\text {theory }}=\left(\mathrm{e}_{\mathrm{a}}^{\mathrm{s}}-\mathrm{e}_{\mathrm{a}}\right)=\frac{\gamma \mathrm{r}_{\mathrm{a}}\left(\mathrm{R}_{\mathrm{n}}-\mathrm{G}\right)}{\rho_{\mathrm{a}} \mathrm{C}_{\mathrm{p}}}
$$

The above equation indicates the theoretical VPD determined by the available energy and aerodynamic resistance under energy balance conditions. It is worth pointing out that when the observed VPD is directly used to derive the potential evaporation, the observed VPD may not be fully controlled by the local energy balance. Comparing the derived theoretical VPD and the observed VPD, two deductions can be made. If $\mathrm{VPD}_{\text {theory }}$ is smaller than the observed VPD, which indicates significant advection effects, then advection enhances ET rate. If $\mathrm{VPD}_{\text {theory }}$ is larger than the observed VPD, it may indicate a humid air flow, in which case advection depresses ET rate.

Through the analysis above, advection would cause either an enhancement or a depression of the local ET rate depending on the nature of the air flow.

\subsection{Methods for correcting EC measurements}


EC provides a direct measurement of surface heat flux, however many field experiments indicate that EC underestimates the latent heat flux. In addition, the observed latent and sensible heat fluxes often fail to reach energy balance (EB) closure as defined by Eq (1), which is often used to evaluate energy balance closure. The underestimation of latent heat flux using EC systems has caused much confusion in EC applications. Twine et al. (2000) proposed two methods to correct the EC measurements for EB closure. In this study, the method of forcing closure based on the Bowen ratio is illustrated. It was assumed the Bowen ratio is correctly observed with the EC system:

$$
\beta=\frac{\mathrm{H}}{\mathrm{LE}}=\frac{\left(\mathrm{R}_{\mathrm{n}}-\mathrm{G}\right)}{\mathrm{LE}}-1=\frac{\mathrm{H}}{\left(\mathrm{R}_{\mathrm{n}}-\mathrm{G}\right)-\mathrm{H}} \approx \frac{\mathrm{H}_{\mathrm{obs}}}{\mathrm{LE}_{\mathrm{obs}}}
$$

where $\beta$ is the Bowen ratio, and $\mathrm{H}_{\mathrm{obs}}$ and $\mathrm{LE}_{\mathrm{obs}}$ represent the sensible and latent heat fluxes observed with EC system. The forcing closure method is as follows:

$$
\begin{aligned}
H_{\text {cor }} & =\frac{\beta}{1+\beta}\left(R_{n}-G\right) \\
L_{\text {cor }} & =\frac{1}{1+\beta}\left(R_{n}-G\right)
\end{aligned}
$$

This method is herein named the Forcing Closure Method for Daytime (FCMD). It is obvious that the forcing closure method is based on the energy balance equation of $\mathrm{Eq}$ (1), which assumes advection is negligible (Figure 1 (A)). However, this assumption may not be applicable under an advective environment where the impact of advection on ET is too large to be ignored. Therefore, it is imperative to derive a correction method for an advective environment. Since observed air temperature, wind speed and VPD are directly used, advection is accounted for in $\mathrm{E}_{\mathrm{p}}$ as defined in Eq. (7). It is still assumed that the ratio between $\mathrm{H}$ and LE is correctly observed with EC system (Figure 1(B)). For daytime with positive sensible heat flux, the Bowen ratio can be written as follows:

$$
\beta=\frac{\mathrm{H}_{\mathrm{obs}}}{\mathrm{LE}_{\mathrm{obs}}} \approx \frac{\mathrm{Ep}}{\mathrm{LE}}-1
$$

The ratio of $\mathrm{LE} / \mathrm{E}_{\mathrm{p}}$ is often called evaporative fraction. Therefore, the correction method is as follows:

$$
\begin{aligned}
L_{\text {cor }} & =\frac{1}{1+\beta} E p \\
H_{\text {cor }} & =\frac{\beta}{1+\beta} E p
\end{aligned}
$$

To facilitate the description later, this method was named the Daytime Correction Method (DCM). The main difference between this method and the FCMD proposed by Twine et al. (2000) is that the forcing energy changed to $E_{p}$. Advection effects are already accounted for in the $E_{p}$ term.

Nighttime ET is an important proportion of daily ET. Tolk et al. (2006b) pointed out that nighttime ET can be as much as $12 \%$ of daily ET in a highly advective environment. Therefore, accounting for nighttime ET in the correction method is essential. Sensible heat flux often shows small or negative values in nighttime, which leads to a Bowen ratio less than zero. The sensible heat flux is often 
responsible for a large portion of energy for night ET. The correction method used for daytime cannot be applied to night time easily. When $\mathrm{H}$ is negative, the Bowen ratio can be written as follows:

$$
\beta=\frac{\mathrm{H}}{\mathrm{LE}} \approx \frac{\mathrm{LE}-\mathrm{Ep}}{\mathrm{LE}}=1-\frac{\mathrm{Ep}}{\mathrm{LE}}=\frac{\mathrm{H}_{\mathrm{obs}}}{\mathrm{LE}_{\mathrm{obs}}}
$$

and the correction method for the nighttime can be derived:

$$
\begin{aligned}
\mathrm{LE}_{\text {cor }} & =\frac{1}{1-\beta} \mathrm{Ep} \\
\mathrm{H}_{\text {cor }} & =\frac{\beta}{1-\beta} \mathrm{Ep}
\end{aligned}
$$

To facilitate the descriptions later, this method was named the Nighttime Correction Method 1 (NCM1). The above method is mainly based on the observations from EC. It is convenient to derive another method for the correction of latent heat flux at night. In normal conditions, the ET process is not only controlled by the available energy but also controlled by the available water. Considering the evaporation from a non-saturated surface, the ratio of actual to potential evaporation can be a good indicator of the water availability. Then, the actual evaporation can be expressed as:

$$
E=f(u)\left(e_{s}-e_{a}\right)=S E_{p}=\operatorname{Sf}(u)\left(e_{s}^{*}-e_{a}\right)
$$

where $f(u)$ is the wind function, $S$ is the water availability index, $e_{s}^{*}$ is the saturation vapour pressure of the surface, $e_{s}$ is the actual vapor pressure of the surface, and $e_{a}$ is the actual vapor pressure of the air. Combined with the energy balance in the vertical direction, the evaporation from a non-saturated surface can be written as:

$$
\mathrm{E}=\left(\frac{\Delta}{\Delta+\frac{\gamma}{\mathrm{S}}}\left(\mathrm{R}_{\mathrm{n}}-\mathrm{G}\right)+\frac{\gamma}{\Delta+\frac{\gamma}{\mathrm{S}}} \mathrm{E}_{\mathrm{a}}\right)
$$

For a wet surface, $\mathrm{S}$ will equal unity and this formula is just the same as the Penman equation. For a very dry surface, $S$ will approach zero, and $\gamma / S$ goes to positive infinity, and the evaporation rate will be close to zero. This equation is similar to the general expression for evaporation derived by Granger and Gray (1989). The difference is that Granger and Gray termed S as the relative evaporation, and they employed an exponential function to determine the relative evaporation. Assuming $\mathrm{S}$ is nearly constant on a daily basis and that $\mathrm{S}$ can be derived from the corrected latent heat flux during the day time, then the latent heat flux at nighttime can be corrected with equation (21). This method was named the Nighttime Correction Method 2 (NCM2).

\section{Study area and data description}

The data used in this study were collected by the USDA-ARS, Conservation and Production Research Laboratory (CPRL), located at Bushland, Texas, USA. Long term observations indicate the study area is subject to dry, hot air and strong winds (mean of $4.3 \mathrm{~m} / \mathrm{s}$ ), which result in mean annual Class A pan evaporation $>2,600 \mathrm{~mm}$, more than four times mean annual precipitation (CPRL records). The crops in this region are mainly corn, sorghum, winter wheat, and cotton. Two large precision monolithic weighing lysimeters (NE01 and SE02) were used to measure ET in the irrigated cotton 
field. Prior to the field experiment, the lysimeters were calibrated and found to be accurate to within $0.04 \mathrm{~mm}$ (Evett et al. 2012b). During this experiment, plant height, plant width and leaf area index were measured periodically (Evett et al., 2012a; Mkhwanazi et al., 2015). The vegetation on the NE01 lysimeter grew faster than the surrounding field and the lysimeter tended to slightly overestimate field ET during day of year (DOY) 203-209 (Alfieri et al. (2012), Evett et al. (2012b)). Uneven measurements of the NE01 lysimeter were identified in DOY 158, 159, 163 and 166. The lysimeter measurements from DOY 158 through 166 do not show a diurnal variation. However, SE02 site did not show such problem. Each lysimeter was equipped with a net radiometer (model REBS Q*7.1, REBS, Radiation and Energy Balance Systems, Bellevue, WA), four pairs of soil thermocouples (model TMTSS-125G-6, Omega Engineering, Inc., Stamford, CT) and soil heat flux plates (model HFT-3, REBS, Radiation and Energy Balance Systems, Bellevue, WA). The soil heat flux plates were installed at $0.08 \mathrm{~m}$ depth at four evenly spaced locations within and between the crop rows. Soil thermocouple pairs were installed at 0.02 and $0.06 \mathrm{~m}$ depth above the soil heat flux plates. Time domain reflectometery (TDR) probes were buried at 0.02, 0.06 and $0.12 \mathrm{~m}$ depth next to each heat flux plate to sense soil water content using the soil-specific calibration of Evett et al. (2005). The TDR data were used to compute the heat capacity of the soil, and this and the thermocouple data were used to correct the heat flux plate data to surface heat flux (accounting for soil heat storage above the soil heat flux plates) as described by Evett et al. (2012c). Two four-component net radiometers (CNR-1, Kipp and Zonen, Delft, The Netherlands) were deployed in the lysimeter fields. However, the observation interval was different for the net radiometer and the four-component net radiometers (observations from the four-component net radiometers were missing in some days). Therefore, the net radiation values (model $Q^{*} 7.1$ ) were adjusted using the calibration based on the four-component net radiometers (CNR-1, Kipp and Zonen, Delft, The Netherlands). Errors related to soil heat flux measurements were reported to be around 20-30\% in many field studies (Heusinkveld et al. 2004; Foken et al. 2006). According to the study from Alfieri et al.(2012), the day time mean of G for the NE site was $50 \mathrm{~W} / \mathrm{m}^{2}$, while the daytime mean of $\mathrm{G}$ averaged over all 10 soil heat flux plates collected at the intensive study site was $62 \mathrm{~W} / \mathrm{m}^{2}$, where the difference was $12 \mathrm{~W} / \mathrm{m}^{2}$. However, large spatial variation in $\mathrm{G}$ was also observed in this experiment, the range of peak values was nearly $40 \mathrm{~W} / \mathrm{m}^{2}$. Two identical EC systems were located in the lysimeter fields. Each EC system consisted of a fast response 3D sonic anemometer (model CSAT3, Campbell Scientific Inc., Logan, UT), a fast response open path infrared gas $\left(\mathrm{H}_{2} \mathrm{O}\right.$ and $\mathrm{CO}_{2}$ ) analyzer (model LI-7500, LI-COR Inc., Lincoln, NE), a fine wire thermocouple (model FW05, Campbell Scientific Inc., Logan, UT), an air temperature/humidity sensor (model HMP45C, Vaisala Inc., Woburn, MA), and a datalogger (model CR3000, Campbell Scientific Inc., Logan, UT). The EC system measured at a frequency of $20 \mathrm{~Hz}$ and 15-min average LE and $\mathrm{H}$ fluxes were computed. Both EC systems were installed at a 2.5-m height above ground. The raw EC data were corrected for buoyancy/density fluctuation effects. This correction is often called the WPL correction (Webb et al. 1980). Because the sensors were installed within specification and there was adequate fetch, the coordinate transformations and the data de-trending were not pursued since the 15-min averaging period was considered short for non-stationary presence. More details of the experiment are available in the paper by Chávez et al. (2009) and Alfieri et al. (2012). The cotton canopy height (h) reached $0.20 \mathrm{~m}$ by 26 June and $0.64 \mathrm{~m}$ by 28 July in 2008 . To be compatible with the temporal interval of the observation data, a linear interpolation technique was employed for the cotton height. The zero plane 
displacement height $\left(\mathrm{d}_{0}\right)$ and the roughness length $\left(\mathrm{Z}_{\mathrm{om}}\right)$ were parameterized by the following equations (Allen et al. 1998):

$$
\begin{aligned}
\mathrm{d}_{0} & =\frac{2}{3} \mathrm{~h} \\
\mathrm{Z}_{\mathrm{om}} & =0.123 \mathrm{~h}
\end{aligned}
$$

The roughness length governing the transfer of heat and vapor was approximated by (Allen et al. 1998):

$$
\mathrm{Z}_{\mathrm{oh}}=0.1 \mathrm{Z}_{\mathrm{om}}
$$

\section{Results}

\subsection{The evaluation of the EC measurements}

Two steps were taken to evaluate the EC measurements. Firstly, the surface energy balance closure was analyzed. Secondly, the latent heat flux observed with EC systems was evaluated by comparison with the precision weighing lysimeter measurements. The statistical measures for the evaluation of EC measurements are listed in Table 1. Figure 2 shows the comparison between $\left(R_{n}-G\right)$ and $(H+L E)$ at the two sites. At site NE01, there were 481 samples used in this comparison, most of the points plotted below the 1:1 line, which illustrates a poor energy balance closure of the surface energy budget observed with the EC system and generally smaller ( H + LE) than the available energy (Rn - G). The slope and the intercept of the fitted line were 0.71 and $14 \mathrm{~W} / \mathrm{m}^{2}$, respectively. The mean value of all $\left(R_{n}-G\right)$ was $190 \mathrm{~W} / \mathrm{m}^{2}$, while the mean value of all $(\mathrm{H}+\mathrm{LE})$ was only $150 \mathrm{~W} / \mathrm{m}^{2}$. The energy balance closure ratio of this site was 0.78 ( $78 \%$ closure). For the SE02 site, 429 samples were used and most of them plotted below the 1:1 line. This site also showed a poor energy balance closure under the advective environment. The slope and the intercept of the fitted line were 0.70 and $5 \mathrm{~W} / \mathrm{m}^{2}$, respectively. The mean value of all $\left(\mathrm{R}_{\mathrm{n}}-\mathrm{G}\right)$ was $181 \mathrm{~W} / \mathrm{m}^{2}$, while the mean value of all $(\mathrm{H}+\mathrm{LE})$ was $133 \mathrm{~W} / \mathrm{m}^{2}$. The energy balance closure ratio was 0.74 .

The comparisons illustrate both sites had poor energy balance closure. According to Twine et al. (2000), errors related to the soil heat flux measurements are random errors and would not contribute to systematic biases in the closure of the surface energy balance. Both $\mathrm{G}$ and Rn were determined with calibrated systems for which no large sources of error are probable. Therefore, underestimation of $\mathrm{H}$ and LE as sensed by the EC systems is likely the main reason for the large discrepancy of the surface energy closure. Therefore, high accuracy latent heat flux measured with another approach is needed to evaluate the EC measurements. In this study, the mass measurements from the two precision lysimeters turned out to be suitable for this assessment. ET rate values $\left(\mathrm{mm} \mathrm{h}^{-1}\right)$, from the lysimeters, were converted into latent heat flux $\left(\mathrm{W} / \mathrm{m}^{2}\right)$ following equation (1) in the paper by Chávez et al. (2009). Figure 3 presents the comparison of latent heat flux derived from EC and precision lysimeter. For the NE01 site, 480 data samples were used and most of the points plotted below the 1:1 line, which clearly illustrates that the EC system underestimated ET. The slope and the intercept of the fitted line are 0.63 and $-3 \mathrm{~W} / \mathrm{m}^{2}$. The mean absolute deviation (MAD) and the root mean square deviation (RMSD) are $75 \mathrm{~W} / \mathrm{m}^{2}$ and $103 \mathrm{~W} / \mathrm{m}^{2}$, respectively. The coefficient of determination $\left(\mathrm{r}^{2}\right)$ was 0.66 . The 
statistical computations further revealed the underestimates of the EC system at NE01 under the advective environment. The underestimates of ET were also found at the SE02 site. There were 429 samples used in the comparison at SE02 site. Most of the points plotted below the 1:1 line, the discrepancy between the two was as large as $200 \mathrm{~W} / \mathrm{m}^{2}$. The slope and the intercept of the fitted line for the points were 0.65 and $-3 \mathrm{~W} / \mathrm{m}^{2}$, respectively. The MAD and the RMSD were $66 \mathrm{~W} / \mathrm{m}^{2}$ and 91 $\mathrm{W} / \mathrm{m}^{2}$. The $\mathrm{r}^{2}$ was 0.71 . Through the interpretation of the analysis shown above, both EC systems showed a poor energy balance closure, and the EC measurements showed a significant underestimation of ET compared with corresponding measurements from the precision lysimeters.

Table 1. Statistical measures for the evaluation of EC measurements.

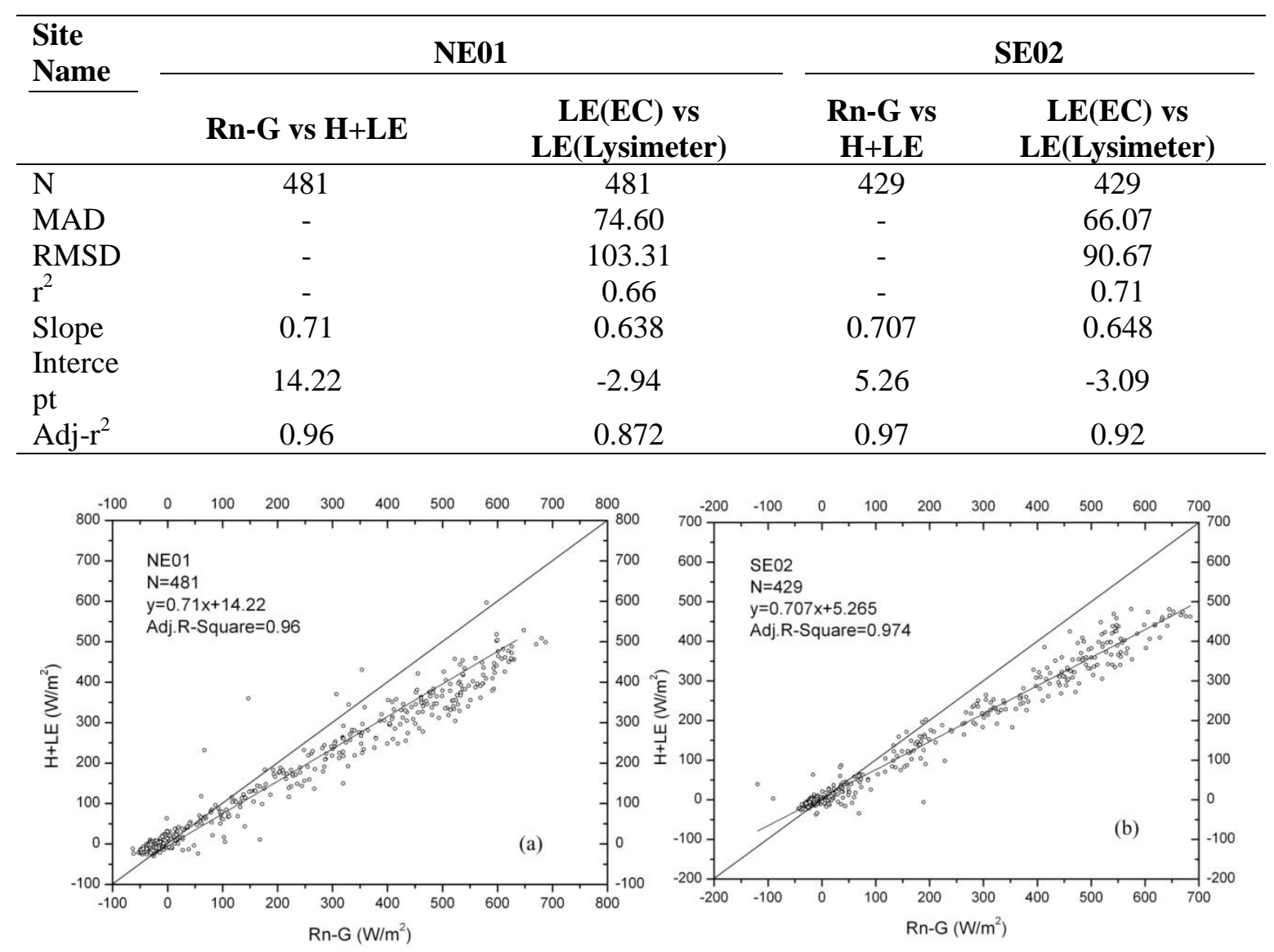

Figure 2. Comparison between $\mathrm{R}_{\mathrm{n}}-\mathrm{G}$ and $\mathrm{H}+\mathrm{LE}$ at two identical sites( (a) NE01 site; (b) SE02 site) 

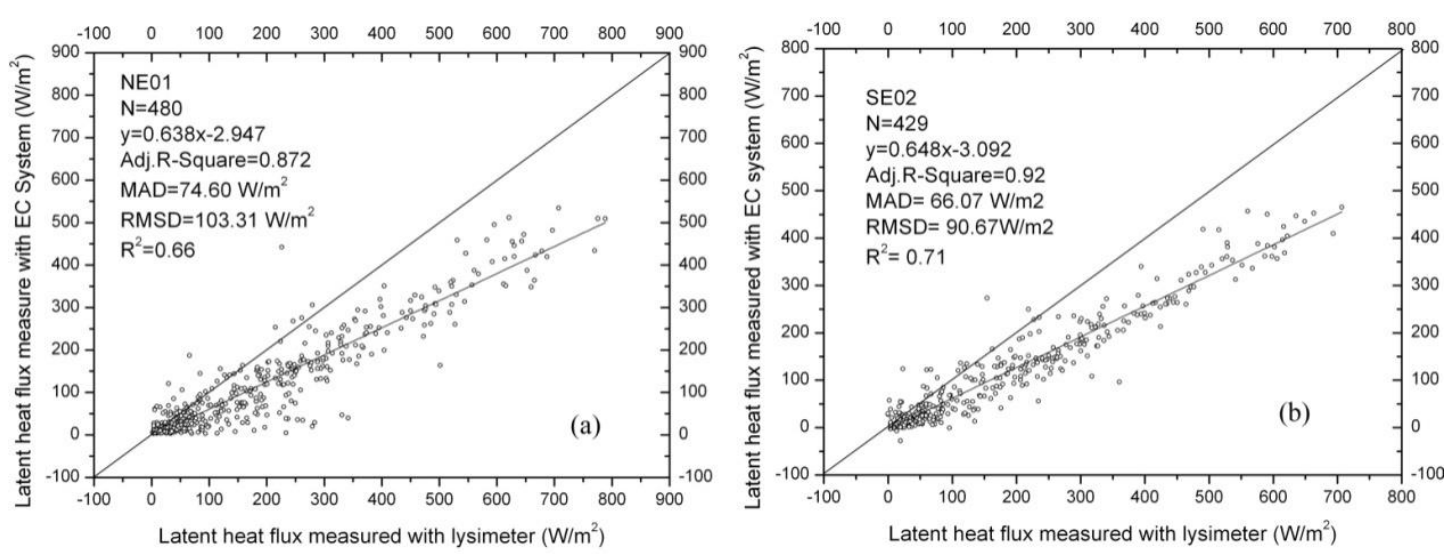

Figure 3. Comparison of latent heat flux measurements from EC systems and precision lysimeters ((a) NE01 site; (b) SE02 site).

\subsection{Characterizing the role of advection}

Advection has a significant impact on ET as has been reported by many researchers. Gay and Bernhofer (1991) found out that advection of sensible heat from the surrounding desert region enhanced ET by $22 \%$ and the amount of ET exceeded the available energy $\left(R_{n}-G\right)$. Spronken-Smith et al. (2000) also found out that the ET across an irrigated urban park exceeded the net radiation in the afternoon due to the oasis effect. In the Regional Advection Perturbations in an Irrigated Desert (RAPID) experiment, Allen (1999) found out that the ratio of ET to $\mathrm{R}_{\mathrm{n}}$ can exceed 1.5 in Kimberly, Idaho, and that the dry air crossing a large desert area may be responsible for this large discrepancy. In the RAPID experiment, De Bruin et al. (2005) also found a poor energy balance closure of the EC system and they used a constant factor of 1.5 to correct both measured H and LE to close the energy balance. They also recognized that this adjustment based on a constant factor was arbitrary. The recent studies revealed that advection can have a great impact on ET and energy balance in arid and semi-arid environments where advection can't be neglected. Here, this issue was further analyzed with the measurements from both the EC systems and the precision lysimeters.

Figure 4 (a) presents a time series comparison of $\left(\mathrm{R}_{\mathrm{n}}-\mathrm{G}\right)$ and $\left(\mathrm{H}+\mathrm{LE}_{\mathrm{lys}}\right)$ at the SE02 site, where $\mathrm{LE}_{\mathrm{lys}}$ is the latent heat flux measured with the precision lysimeter and $\mathrm{H}$ is the sensible heat flux measured with the EC system. The sum of $\left(H+L E_{l y s}\right)$ was greater than the available energy $\left(R_{n}-G\right)$ for these days under advective environmental conditions of very dry air and strong winds. This phenomenon was especially significant in the afternoon of these days. Even though the sensible heat flux was not corrected for the underestimate, $\left(\mathrm{H}+\mathrm{LE}_{\mathrm{lys}}\right)$ still showed to be $50-120 \mathrm{~W} / \mathrm{m}^{2}$ greater than the available energy $\left(R_{n}-G\right)$ around noon. The same phenomenon was also found at the NE01 site. The discrepancy clearly illustrates the occurrence of advection effects and further illustrates that the energy balance equation can't neglect the advection term under advective environment conditions. The effects of advection include two facets: advection not only enhances ET but also modifies the local energy balance as described in equation (1). Figure 4(b) shows a time series of the difference between latent heat flux from lysimeter and eddy covariance system at SE02 site. The difference shows a clear temporal pattern. The maximum of the difference always occurred after noon. Figure 4(c) and Figure 4(d) show a time series of wind speed and water vapor pressure deficit (VPD) in these days. The 
difference between latent heat fluxes from the lysimeter and EC system (Fig. 4b) shows a quite similar temporal pattern as the wind speed and VPD, which indicates advection may be one of the most important reasons for the discrepancy of the latent heat flux between lysimeter and eddy covariance system. Figure 4(d) shows a time series comparison between the observed VPD and the theoretical VPD [see Eq. (10)] at SE02. It is clear the observed VPD is constantly larger than the theoretical VPD. The maximum difference is significant in the late afternoon, which indicates a significant advection effect, which explains the enhanced afternoon diference between LE measured by the lysimeter and LE estimated by the EC system.

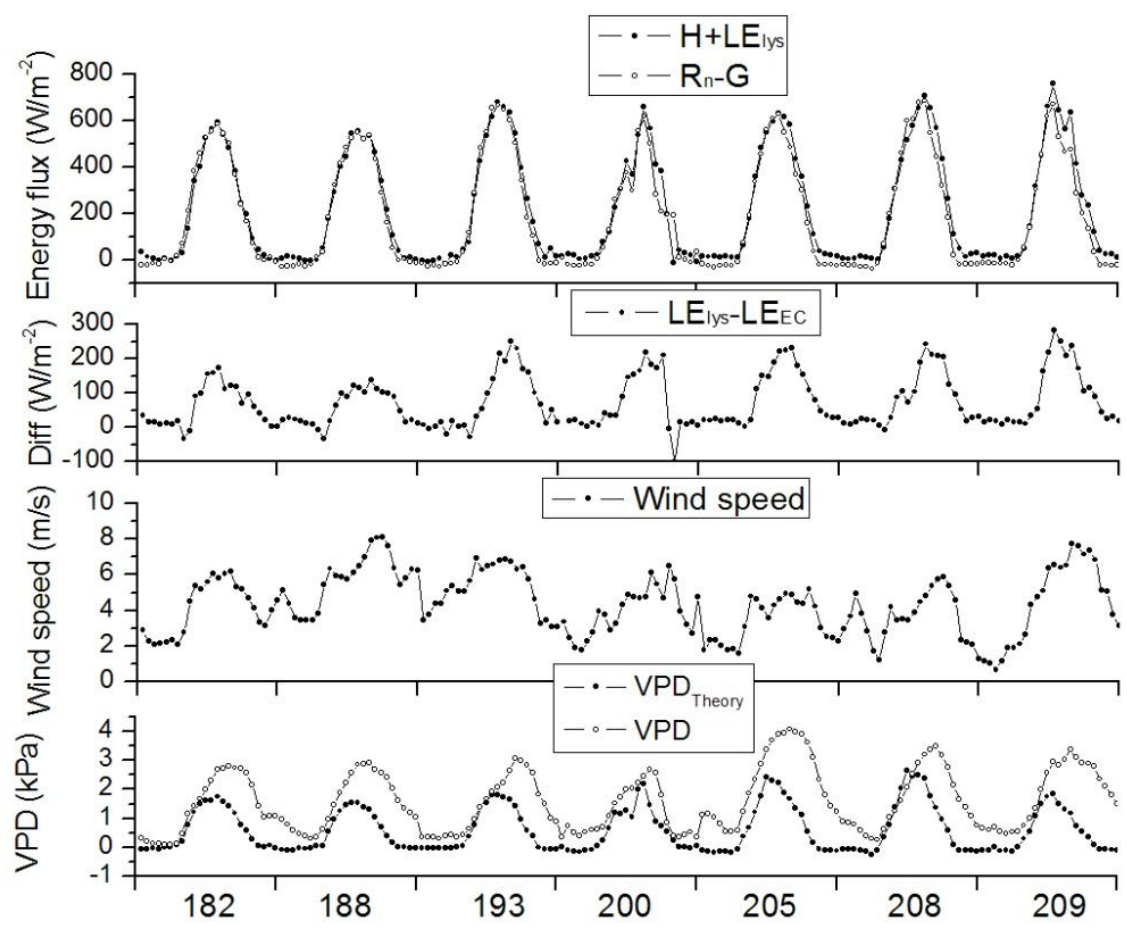

Figure 4. (a)The time series comparison between $\left(\mathrm{R}_{\mathrm{n}}-\mathrm{G}\right)$ and $\left(\mathrm{H}+\mathrm{LE} \mathrm{l}_{\mathrm{lys}}\right)$ at $\mathrm{SE02}$. (b) The time series of the difference between latent heat flux from lysimeter and EC system at SE02. ( $\mathrm{LE}_{\mathrm{lys}}$ represents latent heat flux from lysimeter, while $\mathrm{LE}_{\mathrm{EC}}$ represents latent heat flux from EC system) (c) The time series of wind speed at SE02. (d) The time series of VPD and VPD theory $_{\text {at SE02. }}$

Characterizing the role of advection is imperative in these environments. Equation (7) was applied to characterize the advection effect. Figure 5 shows the diurnal variation of advection in the days of the experiment under the advective environment. The advected energy ranged from $-50 \mathrm{~W} / \mathrm{m}^{2}$ to 280 $\mathrm{W} / \mathrm{m}^{2}$. The largest advection often occurred at approximately 1700 CST (Central Standard Time) of the day at which time the $R_{n}$ greatly declined while the air drying power was still strong. This was consistent with the study by Alfieri et al. (2012) who found a clear temporal pattern of the difference between lysimeter-derived ET and EC-based ET. They found that smaller differences occurred earlier in the day and the maximum difference occurred near 1700 CST. Advection was nearly zero near midnight. Particularly strong advection can be found on the $175^{\text {th }}, 178^{\text {th }}$, and $179^{\text {th }}$ days of the year. 


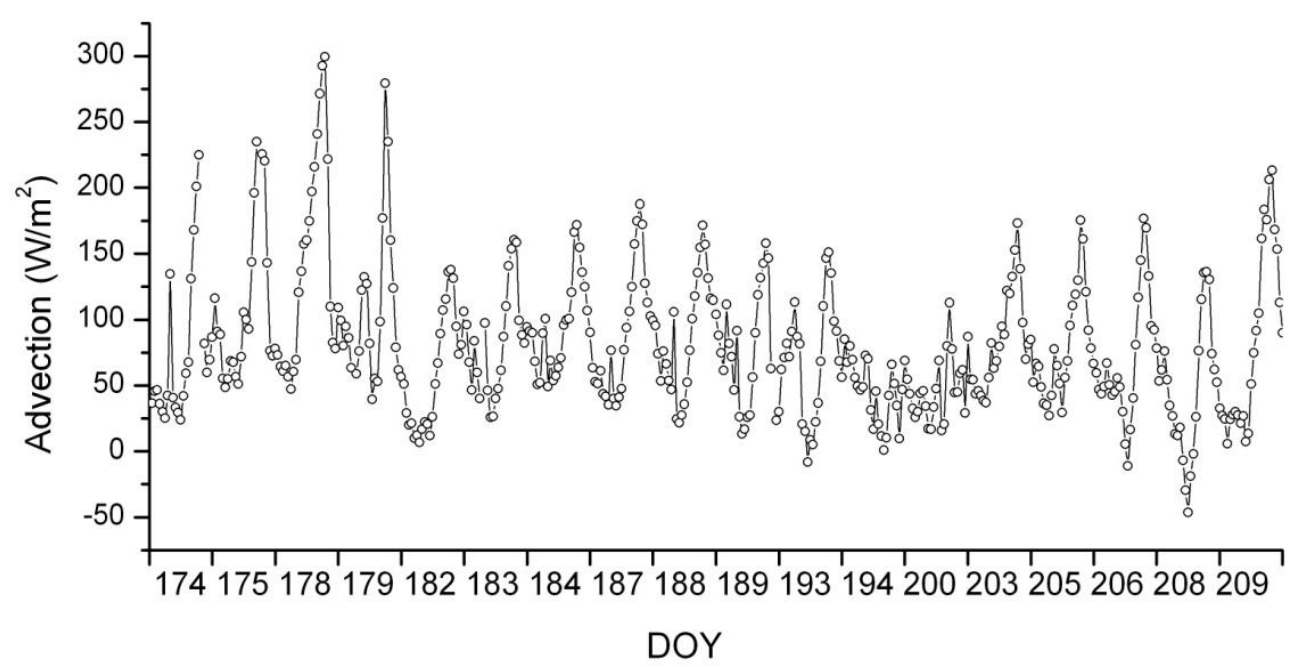

Figure 5. The diurnal behavior of advection at SE02 site under an advective environment.

\subsection{Corrected Latent heat flux accounting for advection}

The analysis in section 4.1 clearly illustrated the underestimation of ET by the EC systems in the advective environment. Section 4.2 further analyzed the advection effect on the local energy balance. The sum of $\mathrm{H}$ and $\mathrm{LE}_{\mathrm{lys}}$ was $50-120 \mathrm{~W} / \mathrm{m}^{2}$ greater than the local available energy $\left(\mathrm{R}_{\mathrm{n}}-\mathrm{G}\right)$. Therefore, the closure forcing methods proposed by Twine et al. (2000) may not be appropriate under such conditions, because these methods are based on the assumption of energy conservation for EC measurements. In this study, the method described in section 2 was applied to correct EC measurements under the advective environment. Assuming the ratio of $\mathrm{H}$ to LE was correctly observed with EC systems, the daytime ET values (0900-1500 CST) were corrected based on the potential ET derived from the Penman-Brutsaert model (Brutsaert, 1982; Katul and Parlange, 1992). The statistical measures for daytime are listed in Table 2. Figure 6 (a) shows the corrected LE compared with latent heat flux measured with the precision lysimeter at NE01. There were 154 samples in this comparison. Most of the points were located close to the 1:1 line. The slope and the intercept of the fitted line to the points were 0.76 and $91 \mathrm{~W} / \mathrm{m}^{2}$, respectively. The $\mathrm{r}^{2}$ was 0.82 . The MAD and RMSD were $56 \mathrm{~W} / \mathrm{m}^{2}$ and $75 \mathrm{~W} / \mathrm{m}^{2}$, respectively. The bias was $9 \mathrm{~W} / \mathrm{m}^{2}$. Figure 6 (b) presents the comparison at SE02. The results seemed better than those from NE01. The 126 data samples were evenly distributed along the 1:1 line which illustrates that the corrected method during daytime was appropriate. The slope and the intercept of the fitted line were 0.90 and $41 \mathrm{~W} / \mathrm{m}^{2}$, respectively. The MAD and RMSD were $36 \mathrm{~W} / \mathrm{m}^{2}$ and $48 \mathrm{~W} / \mathrm{m}^{2}$. The bias was $7 \mathrm{~W} / \mathrm{m}^{2}$. The $\mathrm{r}^{2}$ was 0.89 .

In order to further evaluate the performance of this model, the closure forcing method of Twine et al. (2000) was also applied in this study. Figure 7 shows the corrected results derived from the closure forcing method. At NE01 site, most of the points plotted below the 1:1 line. The slope and the intercept of the fitted line were 0.80 and $35 \mathrm{~W} / \mathrm{m}^{2}$. The MAD and the RMSD were $55 \mathrm{~W} / \mathrm{m}^{2}$ and $73 \mathrm{~W} / \mathrm{m}^{2}$, and the $\mathrm{r}^{2}$ was 0.83 . The bias was $-30 \mathrm{~W} / \mathrm{m}^{2}$. At SE02 site, the slope and the intercept of the fitted line were 0.89 and $8 \mathrm{~W} / \mathrm{m}^{2}$. The MAD and the RMSD were $45 \mathrm{~W} / \mathrm{m}^{2}$ and $55 \mathrm{~W} / \mathrm{m}^{2}$, and the $\mathrm{r}^{2}$ was 0.85 . The bias 
was $-28 \mathrm{~W} / \mathrm{m}^{2}$. Using the mean net radiation from 6 sites and the mean soil heat flux from ten soil heat flux plate measurements, Alfieri et al. (2012) also applied the closure forcing method to correct the observations from 4 July through 7 August. After adjusting the turbulent fluxes to force closure, they still found the adjusted latent heat flux was less than the measurements from lysimeter. They found the mean differences were $76 \mathrm{~W} / \mathrm{m}^{2}$ and $52 \mathrm{~W} / \mathrm{m}^{2}$ for NE01 site and SE02 site, respectively. Comparing the statistical measures in Table 2, the newly developed models showed improved results compared with forcing the energy balance closure at the SE02 site. Results for the SE01 site did not differ much between the two methods.

In further comparision of the two correction methods, we excluded the uneven measurements in DOY 158, 159, 163 and 166. In response, MAD and RMSD for DCM decreased to $54 \mathrm{~W} / \mathrm{m}^{2}$ and 70 $\mathrm{W} / \mathrm{m}^{2}$, respectively, and the $\mathrm{r}^{2}$ decreased to 0.80 . For the closure forcing method, the MAD remained unchanged, RMSD increased to $74 \mathrm{~W} / \mathrm{m}^{2}$, and the $\mathrm{r}^{2}$ decreased to 0.78 . The DCM method showed slightly more improvement than did the closure forcing method. Alfieri et al. (2012) and Evett et al. (2012b) reported the observation problems of the lysimeter at the NE01 site where the vegetation on the lysimeter grew more rapidly than that in the surrounding field. Therefore, statistical indicators of NE01 may not clear reflect the advantage of the newly developed method. However, this observation problem was not found at SE02 site. Thus the statistical indicators at NE02 are more informative of this newly developed model under the advective environment.

Table 2. Statistical measures for daytime (0900-1500 CST) correction.

\begin{tabular}{lcccc}
\hline \multicolumn{1}{c}{ Site Name } & \multicolumn{2}{c}{ NE01 } & \multicolumn{2}{c}{ SE02 } \\
\hline Correction Method & DCM & FCMD & DCM & FCMD \\
N & 154 & 154 & 126 & 126 \\
MAD & 56.23 & 54.69 & 36.44 & 44.70 \\
RMSD & 75.47 & 72.91 & 48.24 & 55.37 \\
Bias & 8.58 & -29.57 & 6.97 & -28.47 \\
$\mathrm{R}^{2}$ & 0.82 & 0.83 & 0.89 & 0.85 \\
Slope & 0.76 & 0.80 & 0.90 & 0.89 \\
Intercept & 90.56 & 35.47 & 40.84 & 8.06 \\
Adjusted ${ }^{2}$ & 0.82 & 0.86 & 0.89 & 0.89 \\
\hline
\end{tabular}



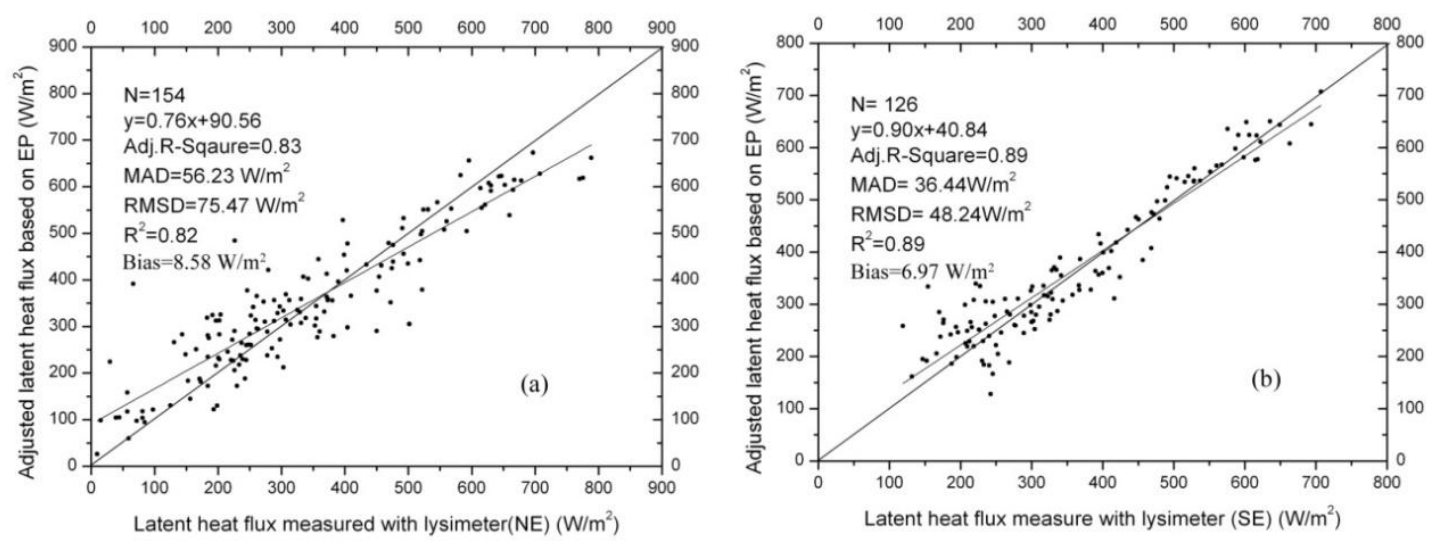

Figure 6. Comparison of latent heat flux measured with lysimeter and adjusted latent heat flux with the proposed method from EC (0900-1500 CST).
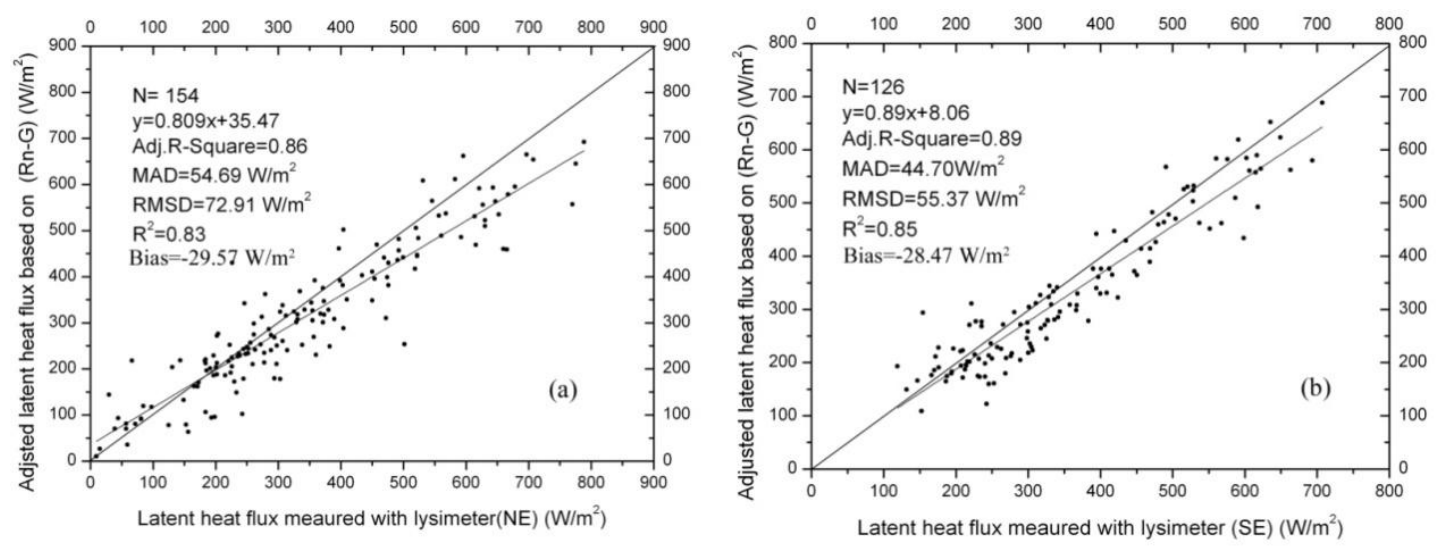

Figure 7. Comparison of latent heat flux measured with lysimeter and adjusted latent heat flux based on the forcing closure method (0900-1500 CST).

Table 3. Statistical measures for nighttime (0000 to 900 and 1500 to 2300 CST) correction.

\begin{tabular}{ccccccc}
\hline Site Name & & \multicolumn{2}{c}{ NE01 } & & \multicolumn{2}{c}{ SE02 } \\
\cline { 1 - 3 } \cline { 6 - 7 } Correction Method & & NCM1 & NCM2 & & NCM1 & NCM2 \\
\hline N & & 326 & 326 & & 303 & 303 \\
MAD & & 51.72 & 41.69 & & 34.15 & 28.15 \\
RMSD & & 77.88 & 60.90 & & 48.69 & 42.74 \\
R $^{2}$ & & 0.534 & 0.72 & & 0.76 & 0.81 \\
Slope & & 0.807 & 0.849 & & 1.01 & 1.01 \\
Intercept & & 18.05 & 14.28 & & 0.437 & 2.7 \\
Adj-R-Square & & 0.603 & 0.73 & & 0.81 & 0.84 \\
\hline
\end{tabular}

Nighttime ET is an important proportion of daily ET in the environment at Bushland (Tolk et al., 2006b). In this study, two methods proposed in section 2 were applied to correct ET values at night. The statistical results are listed in Table 3. Figure 8 presents the comparison of latent heat flux measured with lysimeter and adjusted latent heat flux based on NCM1. For the NE01 site, the NCM1 method showed poorer performance. The MAD and RMSD were $52 \mathrm{~W} / \mathrm{m}^{2}$ and $78 \mathrm{~W} / \mathrm{m}^{2}$, respectively, 
with $r^{2}=0.53$. This poorer performance at NE01 was related to the uneven measurements of lysimeter in the first few days (See Figure 11). Excluding the uneven measurements in DOY 158, 159, 163 and 166, the MAD and RMSD decreased to $45 \mathrm{~W} / \mathrm{m}^{2}$ and $63 \mathrm{~W} / \mathrm{m}^{2}$, respectively, And the $\mathrm{r}^{2}$ increased to 0.71. The NCM1 showed much better results for the SE02 site for which the MAD and RMSD were 34 $\mathrm{W} / \mathrm{m}^{2}$ and $49 \mathrm{~W} / \mathrm{m}^{2}$, respectively. The slope and intercept were 1.01 and 0.437 , respectively, and the $\mathrm{r}^{2}$ was 0.76 .

The application of NCM2 needs an assumption. Assuming the water availability for ET was nearly constant on a daily basis, the $S$ in Eq. (21) can be derived from the corrected ET values in the daytime. The mean value of $\mathrm{S}$ from 0900 to $1500 \mathrm{CST}$ was used to correct the nighttime ET values with computed potential ET values at nighttime. Figure 9 presents the comparison of latent heat flux measured using lysimeters and corrected ET values at nighttime based on NCM2. For the NE01 site, the slope and the intercept of the fitted line were 0.84 and $14 \mathrm{~W} / \mathrm{m}^{2}$. The MAD and the RMSD were 42 $\mathrm{W} / \mathrm{m}^{2}$ and $61 \mathrm{~W} / \mathrm{m}^{2}$, and the $\mathrm{r}^{2}$ was 0.72 . Excluding the uneven measurements in DOY 158, 159, 163 and 166, the MAD and RMSD decreased to $38 \mathrm{~W} / \mathrm{m}^{2}$ and $56 \mathrm{~W} / \mathrm{m}^{2}$, respectively, and the $\mathrm{r}^{2}$ increased to 0.76 . For the SE02 site, most of the values were distributed evenly along the 1:1 line, which illustrates acceptable results for the NCM2 correction method at nighttime. The slope and the intercept of the fitted line were 1.01 and $3 \mathrm{~W} / \mathrm{m}^{2}$. The MAD and RMSD were $28 \mathrm{~W} / \mathrm{m}^{2}$ and $43 \mathrm{~W} / \mathrm{m}^{2}$, and $\mathrm{r}^{2}=$ 0.81 . The correction method performed better at the SE02 site than at the NE01 site. NCM2 showed an improvement compared with NCM1 at both sites.
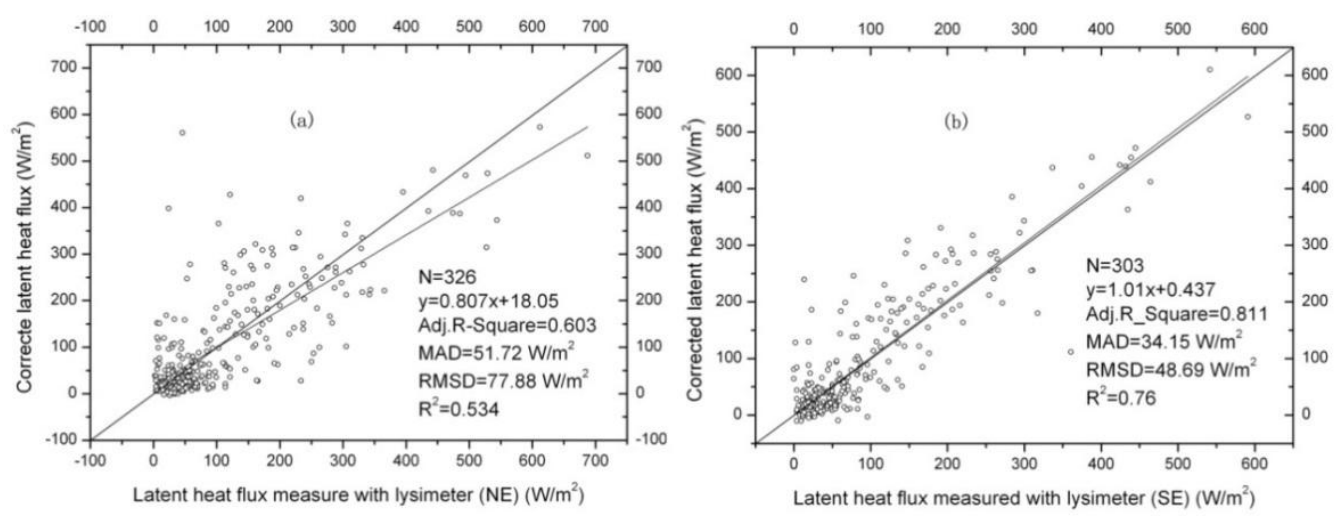

Figure 8. Comparison of latent heat flux measured with lysimeter and adjusted latent heat flux based on NCM1 (0000 to 900 and 1500 to 2300 CST).
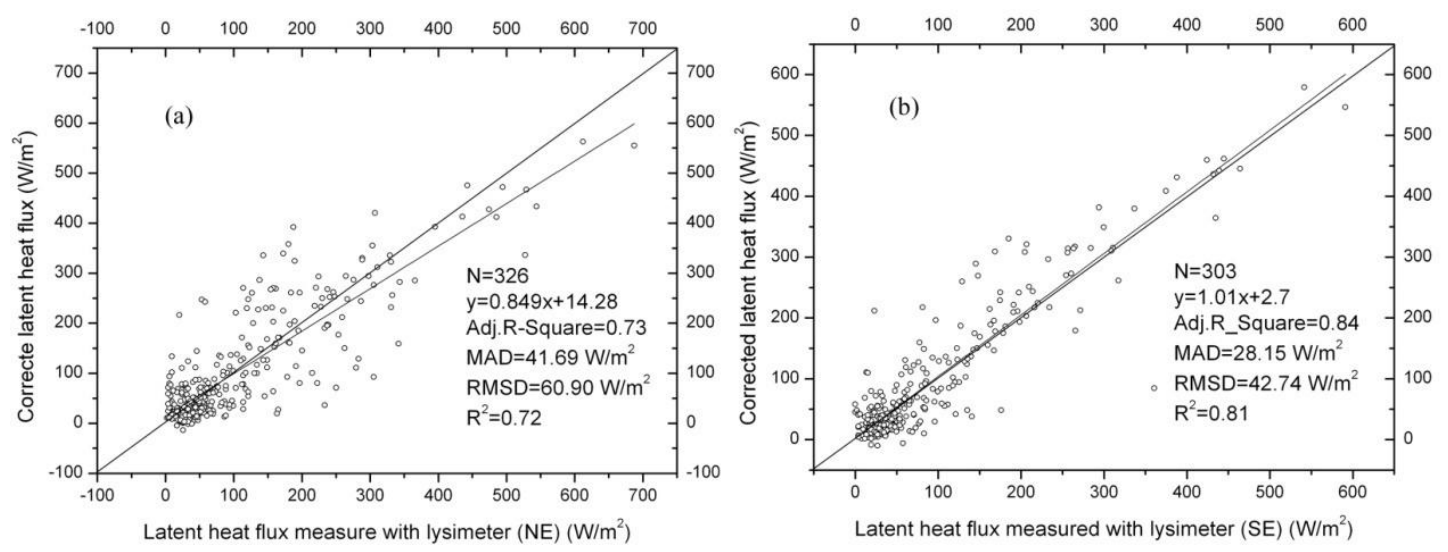
Figure 9. Comparison of latent heat flux measured with lysimeter and adjusted latent heat flux based on NCM2 at night time, (0000 to 900 and 1500 to 2300 CST).

Combining the corrected latent heat flux for both daytime and nighttime, the diel ET was obtained. The statistical measures for diel ET are listed in Table 4. Figure 10 presents the diel ET corrected with DCM and NCM2. It shows the comparison of the corrected latent heat flux to the measurements from the precision lysimeters (including both day time and night time). At NE01, the slope and the intercept of the fitted line were 0.89 and $22 \mathrm{~W} / \mathrm{m}^{2}$; The MAD and the RMSD were $48 \mathrm{~W} / \mathrm{m}^{2}$ and $68 \mathrm{~W} / \mathrm{m}^{2}$, and the $r^{2}=0.85$. Compared with the statistical measures in Table 4 and those in Table 1 , the new correction methods significantly improved the underestimates of EC system at NE01. For comparison, the slope and intercept of the fitted line in Fig. 3a were 0.638 and $-3 \mathrm{~W} / \mathrm{m}^{2}$. An even better result was found at the SE02 site for which most of the data points were evenly distributed along the 1:1 line (Fig. 10b). The slope and the intercept of the fitted line were 0.98 and $7 \mathrm{~W} / \mathrm{m}^{2}$; the MAD and the RMSD were $31 \mathrm{~W} / \mathrm{m}^{2}$ and $44 \mathrm{~W} / \mathrm{m}^{2}$, and the $\mathrm{r}^{2}=0.93$. Compared with the statistics in Table 1 , the new correction methods nearly eliminated the underestimation of $(\mathrm{LE}+\mathrm{H})$ by $\mathrm{EC}$ measurements at the SE02 site. Results from the combination of DCM and NCM1 were comparable to those obtained using DCM and NCM2. Evett et al.(2012) reported the daily total latent heat fluxes from the NE01 site were up to $18 \%$ larger than those from the NE field, which based on the soil water balance method. In this study, we found the latent heat flux from the NE01 lysimeter was $14 \%$ and $8 \%$ larger than DCM+NCM1 and DCM+NCM2 during DOY 203-209. In all, the performance of the corrected method proposed in this study was good, and can be applied to correct EC measurements under advective environments.

Table 4. Statistical measures for diel ET correction.

\begin{tabular}{ccccccc}
\hline Site Name & & \multicolumn{2}{c}{ NE01 } & & \multicolumn{2}{c}{ SE02 } \\
\cline { 1 - 3 } \cline { 5 - 6 } \cline { 5 - 6 } Correction Method & & DCM+NCM1 & DCM+NCM2 & & DCM+NCM1 & DCM+NCM2 \\
\hline N & 480 & 480 & & 429 & 429 \\
MAD & & 53.17 & 47.72 & & 34.82 & 30.59 \\
RMSD & 77.12 & 67.66 & & 48.56 & 44.43 \\
$\mathrm{R}^{2}$ & 0.80 & 0.85 & & 0.915 & 0.93 \\
BIAS & 1.03 & 3.44 & & 3.09 & 4.67 \\
Slope & 0.88 & 0.898 & & 0.992 & 0.988 \\
Intercept & 22.24 & 21.99 & & 4.61 & 6.61 \\
Adj-R-Square & 0.81 & 0.85 & & 0.921 & 0.933 \\
\hline
\end{tabular}



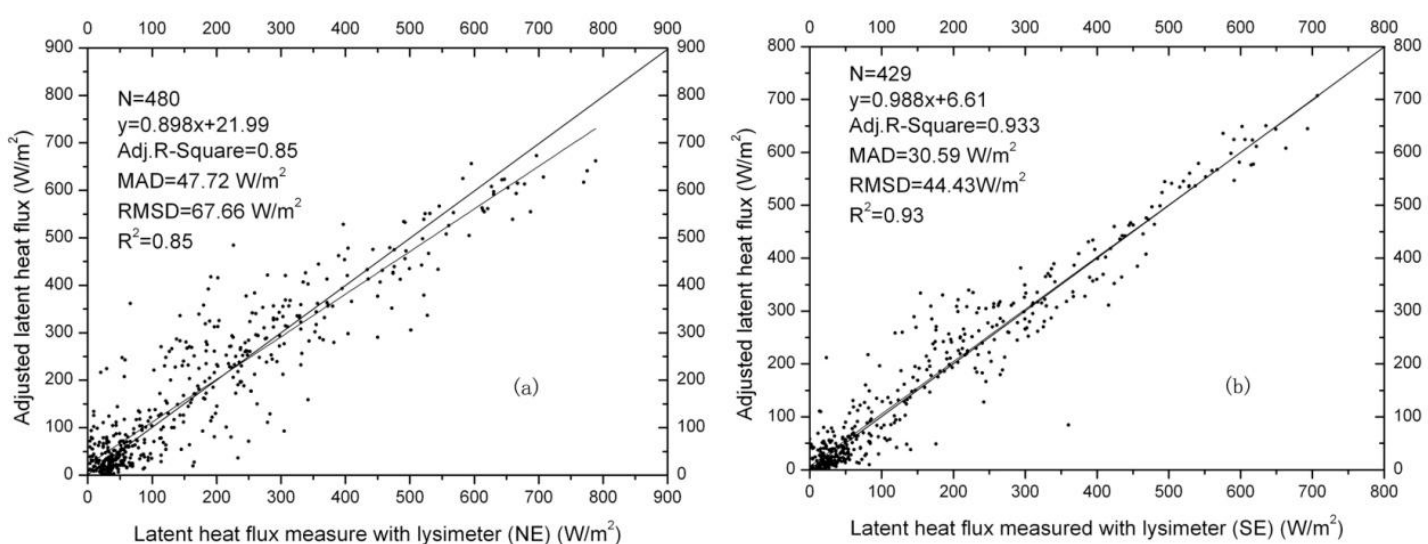

Figure 10. Comparison of corrected latent heat flux from EC with measurements from the precision lysimeters (both daytime and nighttime).
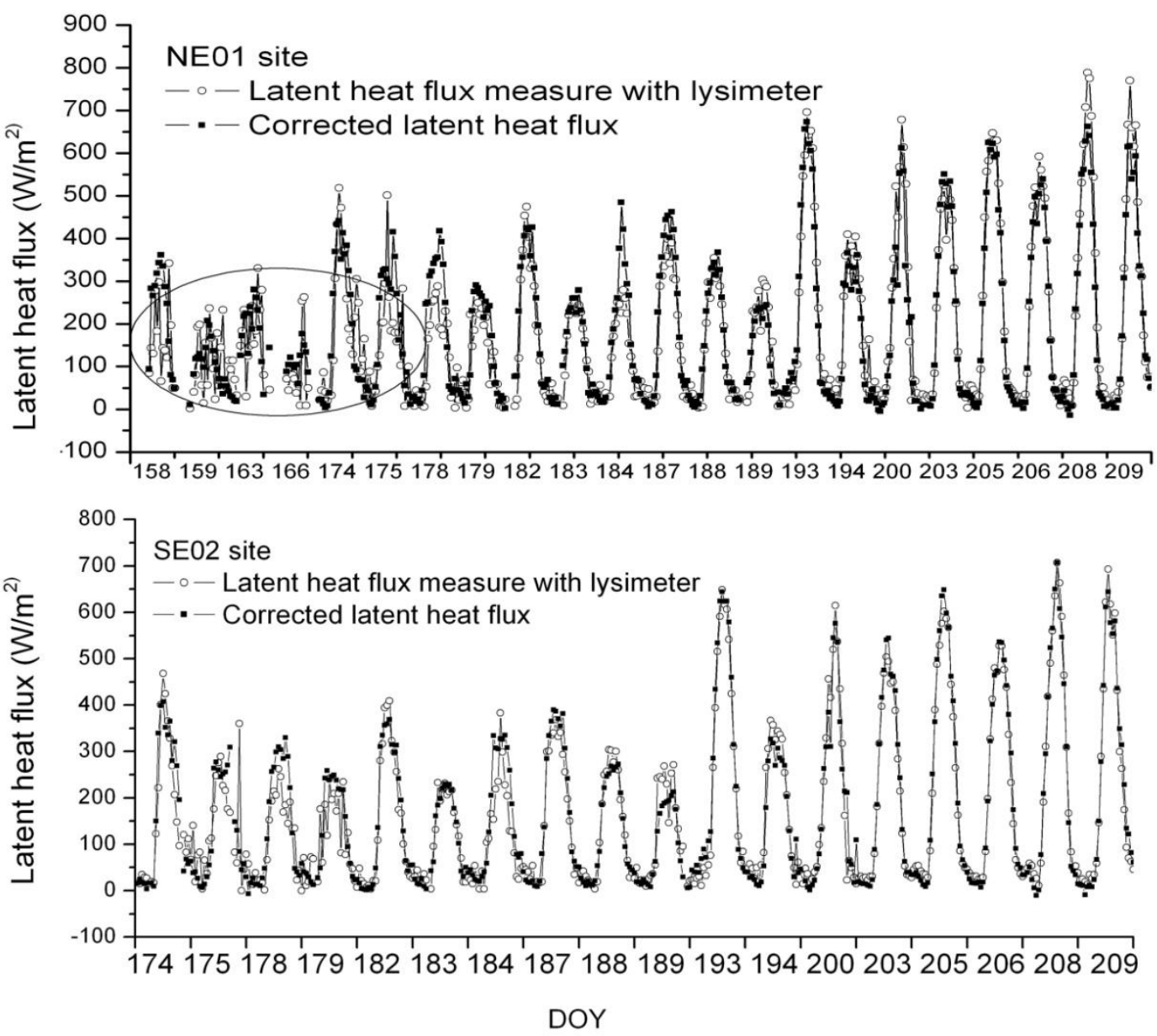

Figure 11.Time series comparison of corrected latent heat flux with the measurements from the precision lysimeters (both daytime and nighttime, circle indicating uneven measurements of the NE01 lysimeter). 


\section{Discussion}

$\mathrm{EC}$ is an important technique to sense the surface energy fluxes and often is applied to validate or evaluate ET models based on remote sensing. However, the problems of lack of energy balance closure and the underestimation of latent heat flux by EC methods have been reported by many (e.g., Allen et al., 2011b; De Bruin et al., 2005). Weighing lysimeters are an important technique to directly measure ET, but they have limited spatial representation and need careful operation. With no assumptions necessary, a weighing lysimeter measure ET through the water mass changes of the soil container, and the observations embody the energy from both local available energy and (local and regional) advected energy from surrounding areas. Comparing the observations from these techniques in a homogenous area would provide more in-depth understanding of land-atmosphere interactions, the energy balance closure problem, and the uncertainties related to the EC technique. In this study, the observations from both lysimeter and EC techniques were compared. There were some uncertainties related to the observations from the lysimeter at the NE01 site, because the plant growth on the lysimeter was larger than that in the field. Alfieri et al. (2012) also reported those observation problems at the NE01 site. However, this problem was not found at SE02 site, and Evett et al. (2012b) found that the lysimeter derived ET at this site matched well the ET derived from the soil water balance in the surrounding cotton field. The EC method showed a large underestimation of ET under advective conditions. This was also reported by Chávez et al. (2009) and Alfieri et al. (2012). The discrepancy between the two techniques could not be completely accounted for either by the imperfect closure of the EC or the uncertainties related to the net radiation and soil heat flux. Evett et al. (2012a) pointed out that the strongly advective conditions (warm dry air from the surrounding area) may be the main reason for the large discrepancy between the two techniques. In this study, a method was proposed to account for the advection in order to correct EC measurements under advective environments and the resulting statistical computations indicated that this approach is applicable under advective environment conditions.

The literature discusses many potential causes of underestimation of sensible and latent fluxes by EC systems. Sensible and latent heat flux can be underestimated by using averaging periods that are too short to capture the low-frequency contributions. Finnigan et al. (2003) reported that increasing the averaging time from $15 \mathrm{~min}$ to $1 \mathrm{~h}$ increased $\mathrm{H}$ by $8 \%$ and $\mathrm{LE}$ by $12 \%$ for measurements at $71 \mathrm{~m}$ above the $40 \mathrm{~m}$ forest at Tumbarumba. These errors increase as the measurement height increases because larger, low frequency eddies then contribute significantly to the fluxes (Foken et al. 2006, Foken et al. 2011). However, using a larger averaging period does not solve the lack of energy balance closure for the EC heat fluxes. During the SMEX02 experiment, Chávez et al. (2005) processed the flux data using half-hour integration periods, and several corrections were performed to the raw EC data, and still a large lack of energy balance closure remained. In this study, 15 min averaging time was used and may cause underestimation of $\mathrm{H}$ and LE. However, the problem related with low frequency errors may not be significant because both EC systems were installed at a $2.5-\mathrm{m}$ height above ground. Over short vegetation, underestimation of low frequency flux contributions appears to represent a minor issue, and smaller increases are expected when measurements are made at lower heights where turbulent transport is dominated by smaller, high-frequency eddies (Foken et al. 2011; Leuning et al. 2012). Alfieri et al. (2012) used the data collected from the same field campaign. One-hour block 
average turbulent fluxes were calculated in their study and the energy balance non-closure problem was still significant. Alfieri et al. (2012) found closure values of 0.87 and 0.85 for NE01 and SE02. The period of the data used in our study was different from that used in Alfieri et al. (2012. The data used in our study are for selected days during the months of June and July 2008, while the data used in Alfieri et al. (2012) were collected during the period from 4 July through 7 August. This is why the closure values are different in the two studies. Nonetheless, using a larger averaging period of one hour did not solve the lack of energy balance closure for the EC heat fluxes.

Advection has a great impact on the local energy balance. Many related field experiments indicated that advection would greatly enhance ET beyond available energy (e.g., Oke, 1979; Tolk et al., 2006a). However, the energy balance equation neglecting advection is widely used and often leads to some confusion, errors, and to the energy balance closure problem. For the advection effects, Brutsaert (1982) provided a good example. He pointed out that the atmospheric boundary layer is almost never uniform, in fact it is continually responding to large-scale weather patterns, which tend to maintain a humidity deficit even over the ocean. However, the problems of EC heat flux underestimation and imperfect EB closure (the energy balance equation neglected advection) are intertwined and lead to inaccuracies when determining ET of a given vegetated surface using EC systems. It is worth noting that the conservation equation was applied to study the energy balance closure problem in recent studies (Kochendorfer and Paw, 2011; Leuning et al., 2012), and these showed great improvement over previous studies. However, due to limited observations and complex interactions between land and the atmosphere, such studies greatly rely on some assumptions. The forced closure method of Twine et al. (2000) is mainly based on the energy balance equation, neglecting advection, and may not apply under advective environmental conditions. In fact, the forced closure method is only a special case of our method under conditions when $\left(R_{n}-G\right)$ equal $E_{p}$.

Although the results appear promising, there are still some limitations in this study. Because of the lack of related auxiliary data, the cotton height of every day was simply derived with a linear interpolation and this would cause some uncertainties in the results. The water availability for ET ( $\mathrm{S}$ in Equation 21) was introduced to estimate ET on a 24-h basis. S was assumed to be constant for a 24-h period. In reality, $S$ is a variable with a diurnal variation. In addition, it was assumed that the net radiation and soil heat flux observed with four pairs of soil heat plates have a sufficient accuracy and a good spatial representation in this study. This may not be true in reality, for the soil heat flux may have large spatial variation (Alfieri et al. 2012).

\section{Summary}

In this study, a new method accounting for advection was proposed to correct EC underestimates of latent heat flux under advective environments. The observations from two identical EC systems as well as two precision weighing lysimeters from the USDA ARS CPRL, Bushland, TX, USA were used in this study. The evaluation of the EC data compared with the lysimeter measurements indicated significant underestimation of the land surface energy fluxes. The energy balance ratio for the two EC sites was 0.78 and 0.74 . The sum of measured latent heat flux from the lysimeter and the measured sensible heat flux from the EC system was $50-120 \mathrm{~W} / \mathrm{m}^{2}$ greater than the local available energy $\left(\mathrm{R}_{\mathrm{n}}-\mathrm{G}\right)$; which clearly illustrates the occurrence of the advection in this environment. The advection effect was 
characterized as ranging from $-50 \mathrm{~W} / \mathrm{m}^{2}$ to $280 \mathrm{~W} / \mathrm{m}^{2}$. The largest advected energy often occurred at approximately 1700 CST when $R_{n}$ greatly declined while the air drying power was still important due to strong wind speeds and dry air masses. The correction method was applied to both sites. In daytime, it was found that the proposed method was more suitable to correct ET under the advective environment than was the closure forcing method based on $\left(R_{n}-G\right)$ and the Bowen ratio from the EC measurements. The improved performance was mainly due to the consideration of the changing effects of the advection in the new method. During nighttime, two new methods were proposed to correct EC measurements. The NCM2 method assumed that the water availability for ET was nearly constant on a daily basis and then employed a revised Penman model to correct the nighttime ET values. The results indicated that this method was capable of correcting ET values at night. Finally, all the corrected values, including both daytime and nighttime corrections, were compared with the lysimeter measurements. At the NE01 site, the slope was 0.90 , MAD and RMSD were $48 \mathrm{~W} / \mathrm{m}^{2}$ and $68 \mathrm{~W} / \mathrm{m}^{2}$, and the $\mathrm{r}^{2}$ was 0.85 . For the SE02 site, the slope was 0.99 , MAD and the RMSD were $31 \mathrm{~W} / \mathrm{m}^{2}$ and 44 $\mathrm{W} / \mathrm{m}^{2}$, and $\mathrm{r}^{2}$ was 0.93 . The proposed approaches resulted in important reductions in EC system underestimates under advective environments and are herein recommended.

\section{Acknowledgements:}

The authors are very thankful to the United States Department of Agriculture (USDA) and the Agricultural Research Service (ARS) Conservation and Production Research Laboratory (CPRL) for the data acquisition and sharing. This work is supported jointly by the Project of Natural Science Foundation of China (41571356, 41171286, 41501415,), the Natural Science Foundation of the USA (Grant No. HRD-0734850) and Key Laboratory of Water Cycle and Related Land Surface Processes, Institute of Geographic Sciences and Natural Resources Research, Chinese Academy of Sciences (No. 2015A006). We gratefully acknowledge support from the USDA-ARS Ogallala Aquifer Program, a consortium between USDA-Agricultural Research Service, Kansas State University, Texas AgriLife Research, Texas AgriLife Extension Service, Texas Tech University, and West Texas A\&M University.

\section{Conflicts of Interest}

The authors declare no conflict of interest.

\section{References and Notes}

1. Agam, N.; Kustas, W.P.; Evett, S.R.; Colaizzi, P.D.; Cosh, M.; McKee, L.G., 2012. Soil heat flux variability influenced by row direction in irrigated cotton. Advances in Water Resources. In press.

2. Alfieri, J.G., W.P. Kustas, J.H. Prueger, L.E. Hipps, S.R. Evett, J. Basara, C.M.U. Neale, A.N. French, P.D. Colaizzi, N. Agam, J.L. Chavez, and T.A. Howell., 2012. On the discrepancy between eddy covariance and lysimetry-based surface flux measurements under strongly advective conditions. Adv. Water Resourc. In press.

3. Allen, R. G., L. S. Pereira, D. Raes, and M. Smith.,1998. Crop evapotranspiration-Guidelines for 
computing crop water requirements-FAO Irrigation and drainage paper 56, FAO, Rome, 300.

4. Allen, R., 1999. Initial Report on Closure Error fromEddy Covariance Systems used in the Regional Advection Perturbations in an Irrigated Desert(RAPID) - Impacts on Evapotranspiration.http://www.kimberly.uidaho.edu/ rallen/equip/rapidrp1.pdf, viewed on 2011,10,15.

5. Allen, R.G., Pereira, L.S., Howell, T.A. and Jensen, M.E., 2011a. Evapotranspiration information reporting: I. Factors governing measurement accuracy. Agricultural Water Management, 98(6): 899-920.

6. Allen, R., Irmak, A., Trezza, R., Hendrickx, J.M.H., Bastiaanssen, W., Kjaersgaard, J., $2011 b$. Satellite-based ET estimation in agriculture using SEBAL and METRIC. Hydrological Processes, 25(26): 4011-4027.

7. Betts, R., Cox, P., Collins, M., Harris, P., Huntingford, C., Jones, C., 2004. The role of ecosystematmosphere interactions in simulated Amazonian precipitation decrease and forest dieback under global climate warming. Theoretical and Applied Climatology, 78(1): 157-175.

8. Brutsaert, W., 1982. Evaporation into the atmosphere: Theory, history, and applications, Springer, New York.

9. Brutsaert, W., 2005. Hydrology: an introduction. Cambridge Univ Press. New York.

10. Brutsaert, W. and Stricker, H., 1979. Advection-Aridity Approach to Estimate Actual Regional Evapotranspiration. Water Resources Research, 15(2): 443-450.

11. Chávez J.L., C.M.U. Neale, L.E. Hipps, J.H. Prueger, and W.P. Kustas. 2005. Comparing aircraftbased remotely sensed energy balance fluxes with eddy covariance tower data using heat flux source area functions. J. of Hydrometeorology, AMS, 6(6):923-940. DOI:10.1175/JJ,467.1

12. Chávez, J.L., Howell, T.A. and Copeland, K.S., 2009. Evaluating eddy covariance cotton ET measurements in an advective environment with large weighing lysimeters. Irrigation Science, 28(1): 35-50.

13. Cleugh, H.A., Leuning, R., Mu, Q.Z. and Running, S.W., 2007. Regional evaporation estimates from flux tower and MODIS satellite data. Remote Sensing of Environment, 106(3): 285-304.

14. De Bruin, H.A.R., Hartogensis, O.K., Allen, R.G. and Kramer, J.W.J.L., 2005. Regional Advection Perturbations in an Irrigated Desert (RAPID) experiment. Theoretical and Applied Climatology, 80(2): 143-152.

15. Deng, X. Z., and C. H. Zhao (2015), Identification of Water Scarcity and Providing Solutions for Adapting to Climate Changes in the Heihe River Basin of China, Adv Meteorol.

16. Deng, X. Z., Q. L. Shi, Q. Zhang, C. C. Shi, and F. Yin (2015), Impacts of land use and land cover changes on surface energy and water balance in the Heihe River Basin of China, 2000-2010, Phys Chem Earth, 79-82, 2-10.

17. Eagleson, P.S.,2002. Ecohydrology: Darwinian expression of vegetation form and function; Cambridge Univ Pr; Page:145-160.

18. Evett, S. R., W. P. Kustas, P. H. Gowda, M. C. Anderson, J. H. Prueger, and T. A. Howell (2012), Overview of the Bushland Evapotranspiration and Agricultural Remote sensing EXperiment 2008 (BEAREX08): A field experiment evaluating methods for quantifying ET at multiple scales, $A d v$ Water Resourc, 50, 4-19.

19. Evett, S.R., J.A. Tolk, and T.A. Howell. 2005. TDR laboratory calibration in travel time, bulk 
electrical conductivity, and effective frequency. Vadose Zone J. 4:1020-1029.

20. Evett, S.R.; Kustas, W.P.; Gowda, P.H.; Anderson, M.C.; Prueger, J.H.; Howell, T.A.,2012a. Overview of the Bushland Evapotranspiration and Agricultural Remote sensing experiment 2008 (BearEX08): A field experiment evaluating methods for quantifying ET at multiple scales. Adv Water Resourc. 50:4-19. http://dx.doi.org/10.1016/j.advwatres.2012.03.010.

21. Evett, S.R., R.C. Schwartz, T.A. Howell, R.L. Baumhardt and K.S. Copeland., 2012b. Can weighing lysimeter ET represent surrounding field ET well enough to test flux station measurements of daily and sub-daily ET? Adv Water Resourc. Adv. Water Resourc. 50:79-90. http://dx.doi.org/10.1016/j.advwatres.2012.07.023.

22. Evett, S.R., N. Agam, W.P. Kustas, P.D. Colaizzi, and R.C. Schwartz. 2012c. Soil profile method for soil thermal diffusivity, conductivity and heat flux: Comparison to soil heat flux plates. Adv. Water Resourc. 50 (2012) 41-54. http://dx.doi.org/10.1016/j.advwatres.2012.04.012.

23. Finnigan, J.J.; Clement, R.; Malhi, Y.; Leuning, R.; Cleugh, H.A., 2003. A re-evaluation of longterm flux measurement techniques part I: averaging and coordinate rotation. Boundary-Layer Meteorology, 107(1): 1-48.

24. Foken, T., 2008. The energy balance closure problem: An overview. Ecological Applications, 18(6): 1351-1367.

25. Foken, T., Wimmer, F., Mauder, M., Thomas, C. and Liebethal, C., 2006. Some aspects of the energy balance closure problem. Atmospheric Chemistry and Physics, 6: 4395-4402.

26. Foken, T.; Aubinet, M.; Finnigan, J.J.; Leclerc, M.Y.; Mauder, M.; Paw U, K.T. ,2011. Results of a panel discussion about the energy balance closure correction for trace gases. Bulletin of the American Meteorological Society, 92(4): ES13-ES18.

27. Gay, L. and Bernhofer, C., 1991. Enhancement of evapotranspiration by advection in arid regions. Hydrological Interactions between Atmosphere, Soil and Vegetation, 204: 147-156.

28. Goutorbe, J., Lebel, T., Tinga, A., Bessemoulin, P., Brouwer, J., 1993. A large scale study of landatmosphere interactions in the semiarid tropics (HAPEX-Sahel). IAHS PUBLICATION: 357-357.

29. Granger, R.J. and Gray, D.M., 1989. Evaporation from Natural Nonsaturated Surfaces. Journal of Hydrology, 111(1): 21-29.

30. Granger, R.J., Pomeroy, J.W. and Parviainen, J., 2002. Boundary-layer integration approach to advection of sensible heat to a patchy snow cover. Hydrological Processes, 16(18): 3559-3569.

31. Guo, Y. and Schuepp, P.H., 1994. An Analysis of the Effect of Local Heat Advection on Evaporation over Wet and Dry Surface Strips. Journal of Climate, 7(5): 641-652.

32. Heusinkveld, B.G., Jacobs, A.F.G., Holtslag, A.A.M. and Berkowicz, S.M., 2004. Surface energy balance closure in an arid region: role of soil heat flux. Agricultural and Forest Meteorology, 122(1-2): 21-37.

33. Howell, T.A., Schneider, A.D. and Jensen, M.E., 1991. History of Lysimeter Design and Use for Evapotranspiration Measurements. Lysimeters for Evapotranspiration and Environmental Measurements: $1-9$.

34. Katul, G.G. and Parlange, M.B., 1992. A Penman-Brutsaert Model for Wet Surface Evaporation. Water Resources Research, 28(1): 121-126.

35. Kochendorfer, J. and Paw, U.K.T., 2011. Field estimates of scalar advection across a canopy edge. Agricultural and Forest Meteorology, 151(5): 585-594. 
36. Kustas, W.P., Anderson, M.C., French, A.N. and Vickers, D., 2006. Using a remote sensing field experiment to investigate flux-footprint relations and flux sampling distributions for tower and aircraft-based observations. Advances in Water Resources, 29(2): 355-368.

37. Kustas, W. and Anderson, M., 2009. Advances in thermal infrared remote sensing for land surface modeling. Agricultural and Forest Meteorology, 149(12): 2071-2081.

38. Lawrence, D.M., Thornton, P.E., Oleson, K.W. and Bonan, G.B., 2009. The partitioning of evapotranspiration into transpiration, soil evaporation, and canopy evaporation in a GCM: Impacts on land-Atmosphere interaction. J.Hydrometeor,8,862-880.

39. Lee, X.H.; Yu, Q.; Sun, X.M.; Liu, J.D.; Min, Q.W.; Liu, Y.F.; Zhang, X.Z. Micrometeorological fluxes under the influence of regional and local advection: a revisit. Agricultural and Forest Meteorology 2004, 122, 111-124.

40. Leuning, R., van Gorsel, E., Massman, W.J. and Isaac, P.R., 2012. Reflections on the surface energy imbalance problem. Agricultural and Forest Meteorology, 156: 65-74.

41. Li, Z. Q., G. R. Yu, X. F. Wen, L. M. Zhang, C. Y. Ren, and Y. L. Fu (2005), Energy balance closure at ChinaFLUX sites, Sci China Ser D, 48, 51-62.

42. Li, Z. H., X. Z. Deng, F. Wu, and S. S. Hasan (2015), Scenario Analysis for Water Resources in Response to Land Use Change in the Middle and Upper Reaches of the Heihe River Basin, Sustainability-Basel, 7(3), 3086-3108.

43. Liston, G.E., 1995. Local Advection of Momentum, Heat, and Moisture during the Melt of Patchy Snow Covers. Journal of Applied Meteorology, 34(7): 1705-1715.

44. Liu, M. L., J. C. Adam, and A. F. Hamlet (2013), Spatial-temporal variations of evapotranspiration and runoff/precipitation ratios responding to the changing climate in the Pacific Northwest during 1921-2006, J Geophys Res-Atmos, 118(2), 380-394.

45. Liu, X., S. F. Wang, H. Xue, and V. P. Singh (2015), Simulating Crop Evapotranspiration Response under Different Planting Scenarios by Modified SWAT Model in an Irrigation District, Northwest China, Plos One, 10(10).

46. Mahrt, L., 1998. Flux sampling errors for aircraft and towers. Journal of Atmospheric and Oceanic Technology, 15(2): 416-429.

47. McCabe, M.F. and Wood, E.F., 2006. Scale influences on the remote estimation of evapotranspiration using multiple satellite sensors. Remote Sensing of Environment, 105(4): 271285.

48. Mkhwanazi, M.; Chávez, J.L.; Andales, A.A. SEBAL-A: A Remote Sensing ET Algorithm that Accounts for Advection with Limited Data. (2015) Part I: Development and Validation. Remote Sens., 7, 15046-15067.

49. Monteith, J.L, 1965. Evaporation and evnironment. In The State and Movement of Water in Living Organisms, Proc. $19^{\text {th }}$ Symp. Swansea, U.K.: Society of Experimental Biology, Combrige Unversity Press.

50. Monteith, J.L, 1975. Vegetation and the atmosphere,Volume 1 Principles, Academic Press, New York.

51. Oke, T.R., 1979. Advectively-Assisted Evapotranspiration from Irrigated Urban Vegetation. Boundary-Layer Meteorology, 17(2): 167-173.

52. Oncley, S.P. et al., 2007. The Energy Balance Experiment EBEX-2000. Part I: Overview and 
energy balance. Boundary-Layer Meteorology, 123(1): 1-28.

53. Parlange, M.B. and Katul, G.G., 1992. An Advection-Aridity Evaporation Model. Water Resources Research, 28(1): 127-132.

54. Penman, H. L., 1948. Natural Evaporation from Open Water, Bare Soil and Grass, Proc R Soc Lon Ser-A, 193(1032), 120-146.

55. Penman, H.L., 1963. Vegetation and Hydrology. Tech. Communication No.53. Commonwealth Bureau of Soils, Harpenden, Commonwealth Agricultural Bureaux, Farnham Royal, Bucks, England, 124pp.

56. Priestley, C. and Taylor, R., 1972. On the assessment of surface heat flux and evaporation using large-scale parameters. Monthly weather review, 100(2): 81-92.

57. Prueger, J.H., Hipps, L.E. and Cooper, D.I., 1996. Evaporation and the development of the local boundary layer over an irrigated surface in an arid region. Agricultural and Forest Meteorology, 78(3-4): 223-237.

58. Rijks, D.A., 1971. Water Use by Irrigated Cotton in Sudan .3. Bowen Ratios and Advective Energy. Journal of Applied Ecology, 8(3): 643-663.

59. Rosenberg, N.J., Blad, B.L. and Verma, S.B., 1983. Microclimate: the biological environment. Wiley-Interscience, New York.

60. Shi, Q. L., S. Y. Chen, C. C. Shi, Z. Wang, and X. Z. Deng (2015), The Impact of Industrial Transformation on Water Use Efficiency in Northwest Region of China, Sustainability-Basel, 7(1), 56-74.

61. Shin, Y. C., and Y. H. Jung (2014), Development of Irrigation Water Management Model for Reducing Drought Severity Using Remotely Sensed Soil Moisture Footprints, J Irrig Drain Eng, 140(7).

62. Shuttleworth, W.J., 2007. Putting the 'vap' into evaporation. Hydrology and Earth System Sciences, 11(1): 210-244.

63. Slatyer, R.; McIlroy, I. 1961 Practical Microclimatology. CSIRO, Melbourne, Australia. Spronken-Smith, R.A., Oke, T.R. and Lowry, W.P., 2000. Advection and the surface energy balance across an irrigated urban park. International Journal of Climatology, 20(9): 1033-1047.

64. Su, H., E. F. Wood, M. F. Mccabe, and Z. Su (2007), Evaluation of remotely sensed evapotranspiration over the CEOP EOP-1 reference sites, J Meteorol Soc Jpn, 85A, 439-459.

65. Su, H., M. F. McCabe, E. F. Wood, Z. Su, and J. H. Prueger (2005), Modeling evapotranspiration during SMACEX: Comparing two approaches for local-and regional-scale prediction, Journal of hydrometeorology, 6(6), 910-922.

66. Tanaka, K., Ishikawa, H., Hayashi, T., Tamagawa, I. and Ma, Y.M., 2001. Surface energy budget at Amdo on the Tibetan Plateau using GAME/Tibet IOP98 data. Journal of the Meteorological Society of Japan, 79(1B): 505-517.

67. Tian, J., H. B. Su, X. M. Sun, S. H. Chen, H. L. He, and L. J. Zhao (2013), Impact of the Spatial Domain Size on the Performance of the T-s-VI Triangle Method in Terrestrial vapotranspiration Estimation, Remote Sens-Basel, 5(4), 1998-2013.

68. Tolk, J.A., Evett, S.R. and Howell, T.A., 2006a. Advection influences on evapotranspiration of alfalfa in a semiarid climate. Agronomy Journal, 98(6): 1646-1654.

69. Tolk, J.A., Howell, T.A. and Evett, S.R., 2006b. Nighttime evapotranspiration from alfalfa and 
cotton in a semiarid climate. Agronomy Journal, 98(3): 730-736.

70. Twine, T.E., Kustas, W.P., Norman, J.M., Cook, D.R., Houser, P.R., Meyers, T.P., Prueger, J.H., Starks, P.J., Wesely, M.L., 2000. Correcting eddy-covariance flux underestimates over a grassland. Agricultural and Forest Meteorology, 103(3): 279-300.

71. Vanino, S., G. Pulighe, P. Nino, C. De Michele, S. F. Bolognesi, and G. D'Urso (2015), Estimation of Evapotranspiration and Crop Coefficients of Tendone Vineyards Using Multi-Sensor Remote Sensing Data in a Mediterranean Environment, Remote Sens-Basel, 7(11), 14708-14730.

72. Wang, J.M., Gao, Y.X., Hu, Y.Q., Shen, Z.B., Mitsuta, Y., Sahasi, K., 1993. An Overview of the Heife Experiment in the Peoples-Republic-of-China. Iahs-Aish P , 397-403.

73. Wang, K., Li, Z. and Cribb, M., 2006. Estimation of evaporative fraction from a combination of day and night land surface temperatures and NDVI: A new method to determine the PriestleyTaylor parameter. Remote Sensing of Environment, 102(3): 293-305.

74. Wang, Z. Q., J. Yang, X. Z. Deng, and X. Lan (2015), Optimal Water Resources Allocation under the Constraint of Land Use in the Heihe River Basin of China, Sustainability-Basel, 7(2), 15581575 .

75. Webb EK, Pearman GI, Leuning R (1980) Correlation of fluxmeasurements for density effects due to heat and water vapour transfer. Quart J Roy Meteorol Soc 106:85-100.

76. Yang, Y. M., H. B. Su, R. H. Zhang, J. Tian, and S. Q. Yang (2012), Estimation of regional evapotranspiration based on remote sensing: case study in the Heihe River Basin, $J$ Appl Remote Sens, 6 .

77. Yang, Y. M., H. B. Su, R. H. Zhang, J. J. Wu, and J. W. Qi (2013), A New Evapotranspiration Model Accounting for Advection and Its Validation during SMEX02, Adv Meteorol.

78. Yang, Y. M., H. B. Su, R. H. Zhang, J. Tian, and L. Li (2015), An enhanced two-source evapotranspiration model for land (ETEML): Algorithm and evaluation, Remote Sens Environ, $168,54-65$. 